OPEN ACCESS

Edited by:

MariaFelice Marina Ghilardi, City University of New York,

United States

Reviewed by: Barry Waterhouse,

Rowan University School of Osteopathic Medicine, United States Amiel Rosenkranz,

Rosalind Franklin University of Medicine and Science, United States Maxine Loh

Rosalind Franklin University of Medicine and Science, North

Chicago, United States, in

collaboration with reviewer $A R$

${ }^{*}$ Correspondence: Paolo Flace paolo_flace@libero.it

Received: 07 January 2021 Accepted: 04 May 2021

Published: 05 August 2021

Citation:

Flace P, Livrea P, Basile GA, Galletta $D$ Bizzoca A, Gennarini G, Bertino $S$, Branca JJV, Gulisano M, Bianconi S, Bramanti A and Anastasi G (2021) The

Cerebellar Dopaminergic System.

Front. Syst. Neurosci. 15:650614. doi: 10.3389/fnsys.2021.650614

\section{The Cerebellar Dopaminergic System}

\author{
Paolo Flace ${ }^{1 *}$, Paolo Livrea ${ }^{2}$, Gianpaolo Antonio Basile ${ }^{3}$, Diana Galletta ${ }^{4}$, \\ Antonella Bizzoca ${ }^{5}$, Gianfranco Gennarini ${ }^{5}$, Salvatore Bertino ${ }^{3}$, \\ Jacopo Junio Valerio Branca ${ }^{6}$, Massimo Gulisano ${ }^{6}$, Simona Bianconi ${ }^{7}$, Alessia Bramanti ${ }^{8}$ \\ and Giuseppe Anastasi ${ }^{3}$
}

\begin{abstract}
${ }^{1}$ Medical School, University of Bari 'Aldo Moro', Bari, Italy, ${ }^{2}$ University of Bari "Aldo Moro", Bari, Italy, ${ }^{3}$ Department of Biomedical, Dental Sciences and Morphological and Functional Images, University of Messina, Messina, Italy, ${ }^{4}$ Unit of Psychiatry and Psychology, Federico II University Hospital, Naples, Italy, ${ }^{5}$ Department of Basic Medical Sciences, Neuroscience and Sense Organs, University of Bari "Aldo Moro", Bari, Italy, ${ }^{6}$ Department of Experimental and Clinical Medicine, University of Firenze, Firenze, Italy, ${ }^{7}$ Physical, Rehabilitation Medicine and Sport Medicine Unit, University Hospital "G. Martino", Messina, Italy, ${ }^{8}$ Scientific Institute for Research, Hospitalization and Health Care IRCCS "Centro Neurolesi Bonino Pulejo", Messina, Italy
\end{abstract}

In the central nervous system (CNS), dopamine (DA) is involved in motor and cognitive functions. Although the cerebellum is not been considered an elective dopaminergic region, studies attributed to it a critical role in dopamine deficit-related neurological and psychiatric disorders [e.g., Parkinson's disease (PD) and schizophrenia (SCZ)]. Data on the cerebellar dopaminergic neuronal system are still lacking. Nevertheless, biochemical studies detected in the mammalians cerebellum high dopamine levels, while chemical neuroanatomy studies revealed the presence of midbrain dopaminergic afferents to the cerebellum as well as wide distribution of the dopaminergic receptor subtypes $\left(\mathrm{DRD}_{1}-\mathrm{DR} \mathrm{D}_{5}\right)$. The present review summarizes the data on the cerebellar dopaminergic system including its involvement in associative and projective circuits. Furthermore, this study also briefly discusses the role of the cerebellar dopaminergic system in some neurologic and psychiatric disorders and suggests its potential involvement as a target in pharmacologic and non-pharmacologic treatments.

Keywords: cerebellum, dopamine, dopamine receptors, non-traditional large neurons, Parkinson's disease, schizophrenia, autism spectrum disorders

\section{INTRODUCTION}

In the mammalian cerebellum, the neurotransmitter systems traditionally involved in the synaptic and extrasynaptic interactions may include the excitatory glutamatergic system (Clements et al., 1987; Batini et al., 1992; Ottersen, 1993; Zhang and Ottersen, 1993; Batchelor et al., 1994; Grandes et al., 1994; Nusser and Somogyi, 1997; Knöpfel and Grandes, 2002; Hioki et al., 2003; SanchezPerez et al., 2005; Benagiano et al., 2011; Mugnaini et al., 2011; Uusisaari and De Schutter, 2011; Mapelli et al., 2015) as well as the inhibitory GABAergic and glycinergic systems (Gabbott et al., 1986; Wuenschell et al., 1986; Batini et al., 1992; Ottersen, 1993; Wisden et al., 1996; Sastry et al., 1997; Benagiano et al., 2000a,b; Flace et al., 2004; Crook et al., 2006; Tabata and Kano, 2006; Uusisaari and De Schutter, 2011; Mapelli et al., 2015), which are both involved in intrinsic and projective cerebellar circuits (Fredette and Mugnaini, 1991; Uusisaari and De Schutter, 2011; Ankri et al., 2015; Mapelli et al., 2015; Gao et al., 2016). Moreover, in several studies, the existence 
of a cerebellar cholinergic system (Jaarsma et al., 1997; Prestori et al., 2013; Zhang et al., 2016) and several neuropeptidergic systems have been demonstrated (King et al., 1992; Joo et al., 2004; Schibusawa et al., 2008; Benagiano et al., 2009; Ito, 2009). Currently, data on the presence and distribution of monoaminergic systems in the mammalian cerebellum are still incomplete and not fully analyzed.

Studies reported in the developmental and adult mammalian cerebellum the presence of extrinsic monoaminergic pathways. Studies have been mainly focused on the cerebellar functional role of serotonin (5-HT) and noradrenaline (NA); as a result, until now, the functional role of dopamine (DA) in the cerebellum has been widely disregarded.

In studies using histofluorescence (Hökfelt and Fuxe, 1969) or immunohistochemical methods through specific 5-HT antiserum, in several mammals, including humans, the presence of a cerebellar serotonergic fiber system (Takeuchi et al., 1982; Kerr and Bishop, 1991; Ottersen, 1993; Kitzman and Bishop, 1997; Flace, 2017, 2019a), composed by 5-HT immunoreactive axonal plexuses of fibers and by neuronal cell bodies and processes distributed in the cerebellar cortical layers and in the deep cerebellar nuclei, has been demonstrated (Takeuchi et al., 1982; Bishop and Ho, 1985; Kerr and Bishop, 1991; Crivellato et al., 1992; Flace, 2017, 2019a).

The cerebellar serotonergic fibers originate mostly by the serotonergic cell groups of the reticular formation $\left(B_{1}-B_{3}, B_{6}\right.$, $\mathrm{B}_{7}$, and $\mathrm{B}_{9}$; Dahlström and Fuxe, 1964; Bishop and Ho, 1985; Törk, 1990, Kerr and Bishop, 1991; Kitzman and Bishop, 1994, 1997). In the cerebellar cortex and the deep cerebellar nuclei, different serotonergic subtype receptors such as $5-\mathrm{HT}_{1 \mathrm{~B}}, 5-\mathrm{HT}_{2 \mathrm{~A}}$, $5-\mathrm{HT}_{2 \mathrm{~B}}, 5-\mathrm{HT}_{3}$, and $5-\mathrm{HT}_{5 \mathrm{~A}}$ have been demonstrated (Duxon et al., 1997; Pasqualetti et al., 1998; Sari et al., 1999; Geurts et al., 2002; Oostland et al., 2013; Marinova et al., 2015). During the development, a role of 5-HT in dendritic growth and synaptic plasticity mechanisms has been demonstrated (Bishop et al., 1988; Oostland and van Hooft, 2013; Oostland et al., 2013).

In the adult cerebellum, 5-HT play a role in the modulation of the GABAergic and glutamatergic signaling (Strahlendorf et al., 1991; Cumming-Hood et al., 1993; Kitzman and Bishop, 1997; Dieudonné and Dumoulin, 2000; Di Mauro et al., 2003; Saitow et al., 2009; Murano et al., 2011). 5-HT decreases the activity of the Purkinje neurons (Kerr and Bishop, 1992) by means of the serotonergic receptor 5-HT1 A (Mitoma and Konishi, 1996, 1999). 5-HT may set PCs at a preferred firing rate by modulation of transient outward h currents (Strahlendorf et al., 1984; Wang et al., 1992).

5-HT is involved in the long-term cerebellar effects, as the modulation of postsynaptic induction of long term depression (LTD), mainly by means of the serotonergic receptors $5-\mathrm{HT}_{2 \mathrm{~A}}$ and $5-\mathrm{HT}_{2 \mathrm{~B}}$, which have been expressed on the Purkinje neurons (Maeshima et al., 1998; Cornea-Hébert et al., 1999).

In addition, these serotonergic receptor subtypes activate phospholipase $\mathrm{C}$, resulting in the production of inositol3 trisphosphate (IP3), which can regulate the threshold of regenerative cycles of $\mathrm{Ca}^{2+}$ elevation (Raymond et al., 2001). In chemical neuroanatomy studies, the presence of noradrenergic innervation in the cerebellum of rodents and primates (including humans; Hökfelt and Fuxe, 1969; Siggins et al., 1971; Landis and Bloom, 1975; Yamamoto et al., 1977; Pasquier et al., 1980; Hayashi, 1987; Pompeiano et al., 1989; Powers et al., 1989; Yew et al., 1995; Rosin et al., 1996; Talley et al., 1996; Gould et al., 1997; Melchitzky and Lewis, 2000) by means of fluorescent histochemistry (Falck and Torp, 1962; Hökfelt and Fuxe, 1969), or by specific antisera for dopamine $\beta$ hydroxylase (DBH), the NA biosynthesizing enzymes has been demonstrated (Fritschy and Grzanna, 1989). Cerebellar noradrenergic fibers mainly originate from the noradrenergic cell groups of the reticular formation $\left(\mathrm{A}_{4}-\mathrm{A}_{7}\right.$; Dahlström and Fuxe, 1964; Hökfelt and Fuxe, 1969; Pickel et al., 1973; Pasquier et al., 1980; Dietrichs, 1988; Powers et al., 1989). Such noradrenergic fibers are localized in the three cerebellar cortical layers and in the deep cerebellar nuclei, oriented so as to generate axonal plexuses (Sachs et al., 1973; Pasquier et al., 1980; Dietrichs, 1985; Felten et al., 1986; Powers et al., 1989; Melchitzky and Lewis, 2000).

In the human developmental cerebellum, at 16-18 and 2628 weeks, a transient expression of noradrenergic neuronal cell bodies and processes occurs in the cerebellar cortex and in the deep cerebellar nuclei has been demonstrated (Yew et al., 1995). In addition, in the cerebellum of mammals, extensive distribution of the $\beta_{2}$ adrenergic subtype receptor (Pompeiano et al., 1989; Voogd et al., 1996) and, to a lesser extent, of $\beta_{1}$, $\alpha_{1}$, and $\alpha_{2}$ adrenergic subtype receptors have been demonstrated (Pompeiano et al., 1989; McCune et al., 1993; Rosin et al., 1996; Talley et al., 1996; Voogd et al., 1996). In the development, it has been found that the cerebellar noradrenergic system influences mainly the GABAergic synaptogenesis (Sievers et al., 1981; Sievers and Klemm, 1982; O'Leary and Leslie, 2003; Happe et al., 2004; Hirono et al., 2014). In the adult cerebellum, NA plays a pivotal role in the modulation of the glutamatergic and GABAergic synaptic signaling (Moises et al., 1983; Woodward et al., 1991; Hirono and Obata, 2006; Hirono et al., 2014; Lippiello et al., 2015). Noradrenaline exerts on the Purkinje neurons two types of influence. An increase of the intracellular levels of cAMP protein kinase-dependent by means on the betaadrenergic receptor (Kano et al., 1992; Cheun and Yeh, 1996); the levels of cAMP can, in turn, enhance a form of neuronal plasticity called rebound potentiation (RP; Kano et al., 1992; Cheun and Yeh, 1996; Kawaguchi and Hirano, 2002). Moreover, NA influences in the Purkinje neurons the expression of the immediate-early genes, c-fos and Jun-B (Pompeiano, 1998). The induction of immediate-early genes in the Purkinje neurons appears to play a role in the long-term biochemical changes involved in the maintenance of cerebellar long-term plasticity such as LTD (Pompeiano, 1998).

On the other hand, currently, the presence and the distribution of a dopaminergic system in the cerebellum and its functional role is controversial or neglected (Oertel, 1993; Ottersen, 1993; Kwong et al., 2000). However, several studies demonstrated the involvement of the cerebellum in DA related neurological and psychiatric disorders, such as Parkinson's disease (PD), schizophrenia (SCZ), autism spectrum disorders (ASD), and drug addiction (Glaser et al., 2006; Andreasen and Pierson, 2008; Mittleman et al., 2008; O'Hallaran et al., 2012; Lewis et al., 2013; Wu and Hallett, 2013; Parker et al., 
2014, Carta et al., 2019; Gil-Miravet et al., 2019; Miquel et al., 2020). Therefore, the goal of the present review is to provide a comprehensive overview of the presence, distribution, and functional role of the cerebellar dopaminergic system, also discussing its potential pathophysiological and clinical implications in some neurological and psychiatric DArelated disorders.

\section{MORPHOLOGICAL ASPECTS OF THE DOPAMINERGIC CEREBELLAR SYSTEM}

Although the presence of a dopaminergic system in the cerebellum is in part predictable, currently, the cerebellum is not strictly considered a dopaminergic area (Glowinski and Iversen, 1966; Lindvall and Björklund, 1974; Beckstead et al., 1979; Ottersen, 1993; Masilamoni et al., 2010). In biochemical studies, high levels of DA in the human postmortem cerebellum (Adolfsson et al., 1979; Roubein and Embree, 1979; Spokes, 1979; Gottfries, 1980) and in the rat and monkey cerebellum were detected (Versteeg et al., 1976; Mefford et al., 1982; Glaser et al., 2006; Quansah et al., 2018). Furthermore, in the mammalian cerebellum, in vivo studies by means of positron emission tomography (PET) revealed a significant presence of selective dopamine transporter ligands (DAT-Ls) (Schoeps et al., 1993; Lundkvist et al., 1995; Hall et al., 1999; Emond et al., 2008; Varrone et al., 2009; Jiang et al., 2019).

Chemical neuroanatomy studies on the detection of dopaminergic neuronal elements in the cerebellum of mammals (including human) makes use of direct antisera against DA and of $\left[{ }^{3} \mathrm{H}\right]$-dopaminergic ligands (Panagopoulos et al., 1991; Panagopoulos and Matsokis, 1994) or antisera against the specific dopaminergic marker, the dopamine transporter (DAT), the plasma membrane monoamine transporter involved in DA synaptic reuptake (Table 1; Melchitzky and Lewis, 2000; Dunnet et al., 2005; Giompres and Delis, 2005; Delis et al., 2008; Kim et al., 2009; Flace et al., 2019b, 2020), the indirect marker of the dopaminergic neurotransmission, the dopamine and adenosine $3^{\prime}-5^{\prime}$-monophosphate (cAMP)-regulated protein $\mathrm{Mr} 32,0000$ (DARPP-32), a protein phosphatase-1 inhibitor involved in dopaminergic neuronal synaptic signaling (Table 1; Alder and Barbas, 1995; López et al., 2010; Nishi and Shuto, 2017), or, indirectly, by means of antisera against not elective markers for DA, such as tyrosine hydroxylase $(\mathrm{TH})$, the rate-limiting enzyme DA biosynthesis, which catalyzes the conversion of L-tyrosine to L-3,4-dihydroxyphenylalanine (L-DOPA) (Table 1; Ikai et al., 1992; Fujii et al., 1994; Melchitzky and Lewis, 2000; White and Thomas, 2012) and vesicular monoamine transporter $2\left(\mathrm{VMAT}_{2}\right)$, the synaptic vesicles transporter of monoamine neurotransmitters such as DA, NA, 5-HT, and histamine (HIS) (Table 1; Kim et al., 2009; Lawal and Krantz, 2013).

During the development of the mouse cerebellar cortex, a transient expression of TH in Purkinje neurons in different ages from postnatal day 3 (P3) to 11 months (M11) has been observed (Fujii et al., 1994). The TH expression appears in the Purkinje neurons at P8 in the cerebellar vermis, increases at P13-P15, reduces at $\mathrm{P} 19$, and then increases again after 1 month of age, reaching a maximum expression at 11 months (Fujii et al., 1994).

In the adult mouse cerebellum, the $\mathrm{TH}$ immunoreactive fibers are in the vermal lobules $\mathrm{V}$ and VI, whereas the lowest numbers are located in lobule $\mathrm{X}$, and in each deep cerebellar nuclei, a dense plexus of $\mathrm{TH}$ immunoreactive varicose fibers has been mainly detected (Table 1; Nelson et al., 1997). Whereas, TH immunoreactive cell bodies of Purkinje neurons have been found in the flocculus, paraflocculus, vermal lobules VI-X, and in the hemispheric lobules IX-X (Table 1; Nelson et al., 1997). In pharmacological studies, in the mouse cerebellum DA specific binding sites of $\left[{ }^{3} \mathrm{H}\right] \mathrm{DA}$ and $\left[{ }^{3} \mathrm{H}\right]$ spiperone has been detected (Panagopoulos and Matsokis, 1994).

Moreover, in the adult mouse cerebellum, specific binding of the DA uptake inhibitor ${ }^{3}[\mathrm{H}] \mathrm{GBR} 12935$ in the paraflocculus, lobules IV, VI, IX, X, and lobule simplex Crus I and II has been detected (Delis et al., 2008). In the cerebellar cortex, the specific binding of ${ }^{3}[\mathrm{H}] \mathrm{GBR} 12935$ was mainly distributed in the molecular layer and in the granular layer, while DAT immunoreactivity has been mainly detected in the cell bodies of the Purkinje neurons and in some neuron types of the deep cerebellar nuclei (Table 1; Delis et al., 2008). Furthermore, in the mouse cerebellum, DARPP-32 immunoreactive Purkinje neuron cell bodies in the laminae of all lobules have been observed (Table 1; Alder and Barbas, 1995).

In the rat cerebellum, the DA immunoreactivity presents a uniform distribution pattern in all lobules, and in the layers of the cerebellar cortex the DA immunoreactivity was mainly detected in the molecular layer in climbing fiber-like forms, while a small number of DA immunoreactive fibers within the Purkinje neuron layer and in the granular layer were found (Table 1; Panagopoulos et al., 1991).

Furthermore, in the rat cerebellum, the TH immunoreactive fibers in the paraflocculus and crus I and II ansiform lobules have been mainly detected (Table 1; Ikai et al., 1992); whereas, a high number of $\mathrm{VMAT}_{2}$ immunoreactive 'puncta' (attributable to axon terminals or short sections of dendrites) has been observed in the lobule IX of the posterior cerebellum (Table 1; Kim et al., 2009).

In the rat cerebellar cortex, a low number $\mathrm{TH}$ immunoreactive fibers variously oriented in the Purkinje neuron layer and in the granular layer has been detected; instead, in the molecular layer, a high number of climbing-like oriented $\mathrm{TH}$ immunoreactive fibers has been observed (Table 1; Takada et al., 1993), and $\mathrm{VMAT}_{2}$ small immunoreactive "puncta" were observed between the Purkinje neuron cell bodies and in the molecular layer in close relationship with the dendritic arborizations of the Purkinje neurons (Table 1; Kim et al., 2009).

Biochemical analysis revealed significant levels of DA in the deep cerebellar nuclei of rat, with the highest DA levels being localized in the fastigial and dentate nuclei (Glaser et al., 2006), which is in line with a morphological study that revealed the presence of DAT immunoreactive fibers in all deep cerebellar nuclei (Delis et al., 2008). Moreover, a wide distribution of DAT immunoreactive fibers in the three layers of the cerebellar cortex and in the deep cerebellar nuclei has been revealed (Delis et al., 2008). 
TABLE 1 | Distribution of the catecholaminergic and dopaminergic markers in the mammalian cerebellum.

\begin{tabular}{|c|c|c|c|c|c|}
\hline $\begin{array}{l}\text { Catecholaminergic and } \\
\text { dopaminergic marker }\end{array}$ & Molecular layer & Purkinje neuron layer & Granular layer & $\begin{array}{l}\text { Deep cerebellar } \\
\text { nuclei }\end{array}$ & $\begin{array}{l}\text { Cerebellar lobules } \\
\text { Larsell, } 1952\end{array}$ \\
\hline $\begin{array}{l}\text { Tyrosine hydroxylase }(\mathrm{TH}) \\
\text { (catecholaminergic marker) }\end{array}$ & $\begin{array}{l}\text { - Fibers } \\
\text { climbing-like oriented } \\
\text { - Fibers in the neuropil }\end{array}$ & $\begin{array}{l}\text { - Purkinje neurons cell } \\
\text { bodies and } \\
\text { processes } \\
\text { (lobulesVI-X), } \\
\text { - Fibers around } \\
\text { Purkinje neuron } \\
\text { cell bodies }\end{array}$ & $\begin{array}{l}\text { - Fibers in the neuropil } \\
\text { - Mossy } \\
\text { fiber rosettes-like }\end{array}$ & $\begin{array}{l}\text { - Fibers in the neuropil } \\
\text { of all nuclei }\end{array}$ & $\begin{array}{l}\text { Lobules I, III, V, VI, VIII, } \\
\text { IX, X, Crus I, Crus II, } \\
\text { paraflocculus }\end{array}$ \\
\hline $\begin{array}{l}\text { Vesicular Monoamine } \\
\text { Transporter } 2\left(\mathrm{VMAT}_{2}\right) \\
\text { - (catecholaminergic marker) }\end{array}$ & $\begin{array}{l}\text { Axon terminals (puncta) } \\
\text { around dendrites of } \\
\text { Purkinje neurons }\end{array}$ & $\begin{array}{l}\text { Axon terminals (puncta) } \\
\text { around Purkinje neuron } \\
\text { cell bodies }\end{array}$ & - & - & Lobule IX B \\
\hline $\begin{array}{l}\text { Dopamine Transporter (DAT) } \\
\text { (dopaminergic marker) }\end{array}$ & $\begin{array}{l}\text { - Fibers in the neuropil } \\
\text { - Dendrites of } \\
\text { Purkinje neurons }\end{array}$ & $\begin{array}{l}\text { - Purkinje neurons cell } \\
\text { bodies and } \\
\text { processes } \\
\text { - Fibers in the neuropil }\end{array}$ & $\begin{array}{l}\text { - Fibers randomly } \\
\text { distributed } \\
\text { - Clusters in the sites } \\
\text { of glomeruli complex } \\
\text { - Granules cell bodies } \\
\text { (occasionally) } \\
\text { - Cell bodies and } \\
\text { processes of } \\
\text { Synarmotic neurons } \\
\text { and of } \\
\text { perivascular neurons }\end{array}$ & $\begin{array}{l}\text { - Fibers and puncta } \\
\text { (axon terminals) } \\
\text { - Cell bodies and } \\
\text { processes of } \\
\text { projective and } \\
\text { associative neurons } \\
\text { in all nuclei }\end{array}$ & $\begin{array}{l}\text { All lobules, (lobules VII, } \\
\text { IX in human) }\end{array}$ \\
\hline $\begin{array}{l}\text { Dopamine and Adenosine } \\
3^{\prime}-5^{\prime} \text {-monophosphate } \\
\text { (cAMP) Regulated Protein } \\
\text { Mr 32,000 (DARPP-32) } \\
\text { (indirect } \\
\text { dopaminergic marker) }\end{array}$ & $\begin{array}{l}\text { Dendrites of Purkinje } \\
\text { neurons }\end{array}$ & $\begin{array}{l}\text { Purkinje neurons cell } \\
\text { bodies and processes }\end{array}$ & - & - & All lobules \\
\hline
\end{tabular}

In addition, DARPP-32 immunoreactive dendritic arborization of the Purkinje neurons in the molecular layer of all cerebellar lobules has been observed (Table 1; Alder and Barbas, 1995).

In the rat cerebellar cortex, the presence of $\mathrm{TH}$ immunoreactive cell bodies of Purkinje neurons has been demonstrated in the lobules $\mathrm{I}$ and $\mathrm{X}$ of the vermis, in the paraflocculus, and in crus I and II ansiform lobules (Table 1; Takada et al., 1993) Instead, Kim et al. (2009) evidenced the presence of TH immunoreactive cell bodies of Purkinje neurons predominantly in the lobules VIII-X and a discontinuous presence in the lobules VI and VII, whereas a high number of DAT immunoreactive cell bodies of Purkinje neurons has been detected in the lobule IX of the posterior cerebellum (Table 1; Kim et al., 2009).

In the opossum cerebellum, most of $\mathrm{TH}$ immunoreactive fibers have been found in the lobules III-VIII of the vermis and, to a lesser extent, in lobules I and X (Table 1; Nelson et al., 1997). Moreover, in the opossum cerebellar cortex, the TH immunoreactive fibers were mainly localized in the Purkinje neurons layer; they surround the cell bodies of the Purkinje neurons or run parallel to the plane of the Purkinje neuron layer, whereas, in the molecular layer, only a small amount was detected (Table 1; Nelson et al., 1997), and in the granular layer, the $\mathrm{TH}$ immunoreactive fibers featured a random distribution (Nelson et al., 1997).
In addition, a moderate number of randomly distributed $\mathrm{TH}$ immunoreactive fibers has been detected in the deep cerebellar nuclei (Nelson et al., 1997).

In the cat cerebellum, the highest density of $\mathrm{TH}$ immunoreactive fibers were distributed in the vermal lobules $\mathrm{V}$ and VI and in the hemispheric lobules VI and crus I and II; meanwhile, the lowest density of fibers has been observed in lobules I-III and VIII-X (Table 1; Nelson et al., 1997). In the cat cerebellar cortex, the high density of TH immunoreactive fibers have been observed in the granular layer, where they present a random orientation, and in the Purkinje neurons layer, where they surround the cell bodies of the Purkinje neurons have been observed. Instead, in the molecular layer, only a few densities of $\mathrm{TH}$ immunoreactive fibers with a perpendicular orientation that often extend radially to the surface of the pial surface of the cortex have been detected (Table 1; Nelson et al., 1997). Finally, a moderate density of $\mathrm{TH}$ immunoreactive varicose fibers in the deep cerebellar nuclei have been also found (Table 1; Nelson et al., 1997).

In the monkey cerebellum, we found a low density of $\mathrm{TH}$ immunoreactive fibers to be distributed in the lobules of the vermis and of both cerebellar hemispheres, whereas the DAT immunoreactive fibers were only observed in the vermis of the following lobules II, III, IV, VIIIA, VIIIB, IX, and X (Table 1; Melchitzky and Lewis, 2000).

In the monkey cerebellar cortex, a low density of $\mathrm{TH}$ immunoreactive fibers in the granular layer and in the molecular 


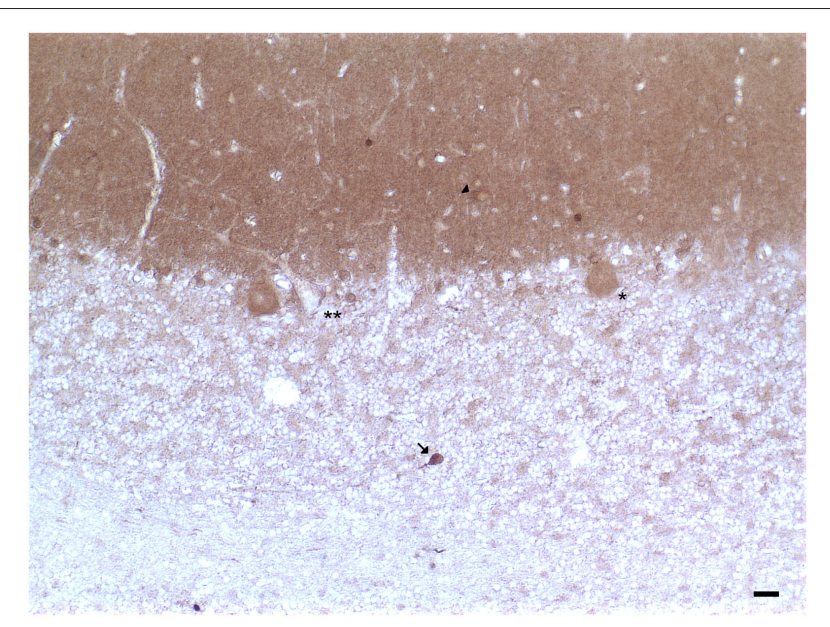

FIGURE 1 | Dopamine transporter (DAT) immunoreactivity in the cerebellar cortex. The DAT immunoreactivity is detectable in neuronal bodies and processes of all the layers of the cerebellar cortex. In the molecular layer, DAT immunoreactivity in basket neurons (arrowheads); primary and secondary trunks dendritic and apical dendrites of Purkinje neurons; immunonegative stellate neurons, fine clusters of DAT immunoreactivity in the neuropil of the layer. In the Purkinje neuron layer, DAT immunoreactive Purkinje neuron cell body (single asterisk), DAT immunonegative Purkinje neuron (double asterisk). In the granular layer, DAT immunoreactivity in space of Held, DAT immunoreactivity in the cell body, and axon-like processes of the synarmotic neuron (arrow). (Scale bar: $25 \mu \mathrm{m})$. layer, has been detected while a higher density of TH plexuses and axonal terminals just beneath the Purkinje neuron cell bodies has been found. Conversely, DAT immunoreactive fibers to be randomly distributed in the granular layer; however, we also found forming plexuses around the deep pole of the cell bodies of the immunonegative Purkinje neurons has been observed. In contrast, in the molecular layer, no DAT immunoreactive fibers have been detected (Table 1; Melchitzky and Lewis, 2000).

Currently, in the monkey cerebellum studies, there is no evidence that proves the existence of dopaminergic neurons. Despite this, a biochemical study demonstrated significant levels of DA in all deep cerebellar nuclei, and the highest levels have been detected in the interpositus and dentate nuclei, (Glaser et al., 2006). Furthermore, in all cerebellar lobules of the monkey cerebellar cortex, a wide presence of DARPP-32 immunoreactive cell bodies and dendritic arborizations of Purkinje neurons has been detected (Table 1; Alder and Barbas, 1995).

In the human cerebellum, immunohistochemical experiments revealed the presence of DAT immunoreactive fibers and neuronal cell bodies in lobules VII and IX (crus I and II, ansiform lobules, and tonsilla) and in the dentate nucleus (Table 1; Figures 1, 2; Flace, 2017, 2019b, 2020; Flace et al., 2018a, 2019b, 2020). There is a significant presence of DAT immunoreactive dendritic arborization of the Purkinje neurons in the molecular layer of the human cerebellar cortex (Table 1; Figure 1). Moreover, the DAT immunoreactivity has been detected in form of clusters in the neuropil among the space

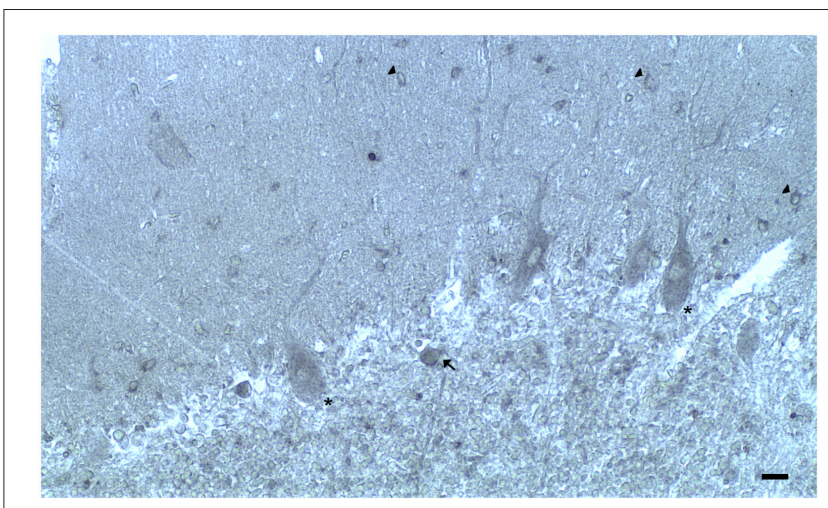

FIGURE 2 | Dopamine receptor type $2\left(\mathrm{DRD}_{2}\right)$ immunoreactivity is observable in neuronal bodies and processes in the layers of the cerebellar cortex. In the $\mathrm{ML}: \mathrm{DRD}_{2}$ immunoreactive basket and stellate neuron cell bodies (arrows), $\mathrm{DRD}_{2}$ immunoreactive primary, secondary, and apical dendrites of Purkinje neurons, $\mathrm{DRD}_{2}$ immunoreactive Purkinje neuron cell bodies (single asterisk). In the granular layer, $\mathrm{DRD}_{2}$ immunoreactivity in space of Held; $\mathrm{DRD}_{2}$ immunoreactive Golgi neuron cell body (arrow) (Scale bar: $20 \mu \mathrm{m})$.

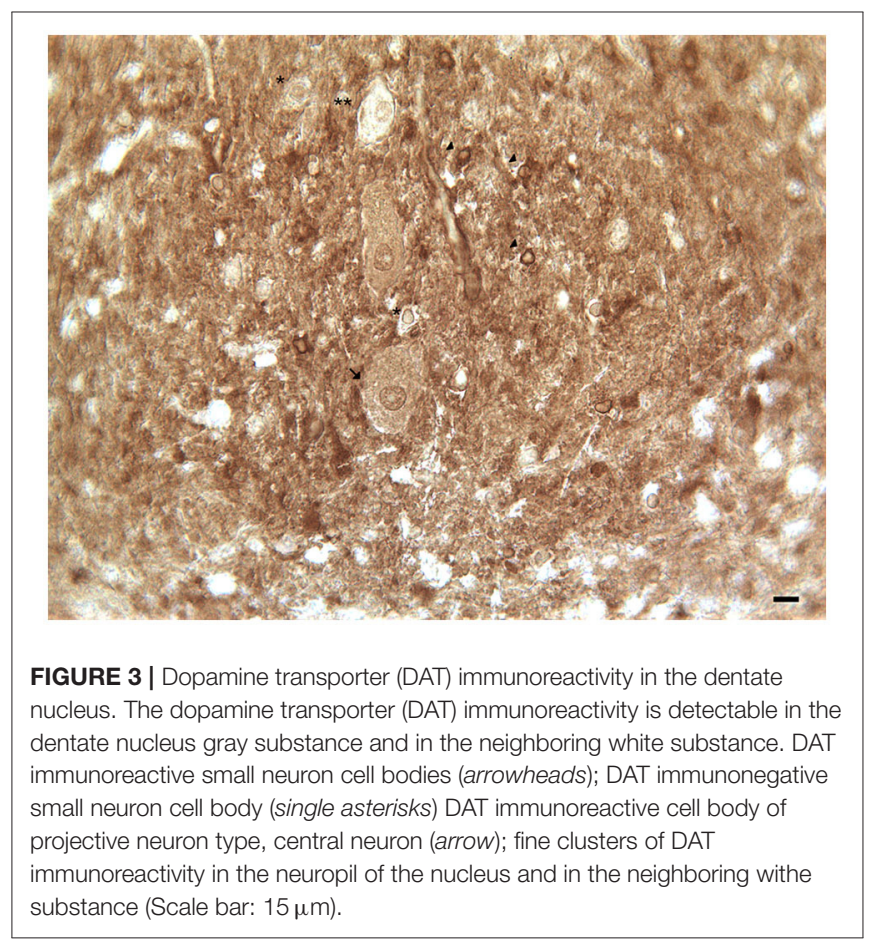

of Held, the sites of the cerebellar glomeruli (Table 1; Figure 1; Flace, 2017, 2019b, 2020; Flace et al., 2018a, 2019b, 2020).

In addition, the DAT immunoreactivity in the cell bodies of Purkinje neurons and of synarmotic neurons (Neuron of Landau) has been also detected (Table 1; Figure 1). This latter, one of the non-traditional large neuron granular layers was involved in corticocerebellar and in corticonuclear projective circuits (Flace et al., 2004, 2018a, 2019b, 2020; Ambrosi et al., 2007; Flace, 2017, 2019a,b, 2020). The DAT immunoreactivity 
TABLE 2 | Distribution of the dopaminergic receptor subtypes in the mammalian cerebellum.

\begin{tabular}{|c|c|c|c|c|}
\hline $\begin{array}{l}\text { Dopamine receptor } \\
\text { subtypes }\end{array}$ & Molecular layer & Purkinje neuron layer & Granular layer & Deep cerebellar nuclei \\
\hline $\begin{array}{l}\text { Dopamine Receptor D1 } \\
\left(\mathrm{DRD}_{1}\right)\end{array}$ & $\begin{array}{l}\text { - Stellate and Basket neuronal cell } \\
\text { bodies and processes } \\
\text { - Dendrites of the Purkinje neurons } \\
\text { - Fine clusters of puncta } \\
\text { (axon terminals) }\end{array}$ & $\begin{array}{l}\text { - Purkinje neuron } \\
\text { cell bodies }\end{array}$ & - & $\begin{array}{l}\text { - Projective and associative } \\
\text { neurons cell bodies and } \\
\text { processes in the } \\
\text { dentate nucleus }\end{array}$ \\
\hline $\begin{array}{l}\text { Dopamine Receptor D4 } \\
\left(\mathrm{DRD}_{4}\right)\end{array}$ & - & - & $\begin{array}{l}\text { Clusters in the neuropil in } \\
\text { the glomeruli complex sites }\end{array}$ & - \\
\hline $\begin{array}{l}\text { Dopamine Receptor D5 } \\
\left(\mathrm{DRD}_{5}\right)\end{array}$ & $\begin{array}{l}\text { - Stellate and Basket neuronal cell } \\
\text { bodies and processes } \\
\text { - Dendrites of the Purkinje neurons } \\
\text { - Fine clusters of puncta } \\
\text { (axon terminals) }\end{array}$ & $\begin{array}{l}\text { - Purkinje neuron } \\
\text { cell bodies }\end{array}$ & - & - \\
\hline
\end{tabular}

in the cell bodies of few granules has been also detected (Flace et al., 2019a,b, 2020). Moreover, DAT immunoreactive nerve fibers variously oriented in the subcortical white substance, has been detected (Figure 1; Flace et al., 2019a,b, 2020). In the dentate nucleus, the DAT immunoreactivity in neuronal cell bodies and processes of different neuron types has been detected (Table 1; Figure 3); the small neuron type is involved in intrinsic circuits, the medium neuron type (Table 1; Figure 3) mainly involved in intrinsic and also in extrinsic circuits, and four different large neuron types, which include the central neuron, the border neuron, the intermediate asymmetrical neuron, and the intermediate fusiform neuron, involved in projective circuits of the dentate nucleus (data not showed; Chan-Palay, 1977; Maric, 2010; Ristanović et al., 2010; Flace et al., 2017, 2019b, 2020; Flace, 2018). Dopamine transporter immunoreactivity in neuronal cell bodies and processes of the perivascular neuron type has also been observed, a neuron type may be involved in regulatory mechanisms of blood-brain barrier (BBB) permeability and in volume transmission mechanisms (data not showed; Flace et al., 2004; Ambrosi et al., 2007; Flace, 2017, 2018, 2019b, 2020).

Furthermore, through different methods in the cerebellum of mammals, a wide distribution of the dopaminergic receptor subtypes $\left(\mathrm{DRD}_{1}-\mathrm{DRD}_{5}\right)$ has been observed (Table 2; Camps et al., 1989; Cortés et al., 1989; Levant, 1998; Barili et al., 2000; Kiss et al., 2011; Flace et al., 2019b, 2020). A broad expression of all the dopaminergic receptor subtypes $\left(\mathrm{DRD}_{1}-\mathrm{DRD}_{5}\right)$ has been demonstrated in the rodent and human cerebellum (Table 2;
Martres et al., 1985; Camps et al., 1990; Mengod et al., 1992; Panagopoulos and Matsokis, 1994; Ricci et al., 1995a,b, 1996; Vessotskie et al., 1997; Levant, 1998; Barili et al., 2000; Khan et al., 2000; Hurley et al., 2003; Delis et al., 2004; Kim et al., 2009; Flace, 2017, 2018, 2019b; Flace et al., 2018a, 2019a,b, 2020).

In the three layers of the cerebellar cortex, the dopaminergic receptor subtypes present a different distribution pattern. In the molecular layer, immunoreactivity to $\mathrm{DRD}_{2}, \mathrm{DRD}_{3}$, and $\mathrm{DRD}_{5}$ receptors in the cell bodies and processes of stellate neurons, basket neurons, and in the dendritic arborizations of the Purkinje neurons has been detected (Table 2; Figure 2). Moreover, in the neuropil of the molecular layer, fine clusters of $\mathrm{DRD}_{2}$ immunoreactivity were detected (Table 2; Figure 2; Camps et al., 1990; Ricci et al., 1995b, 1996; Khan et al., 1998; Levant, 1998; Barili et al., 2000; Flace et al., 2018a, 2019a,b, 2020).

In the Purkinje neuron layer, $\mathrm{DRD}_{1}, \mathrm{DRD}_{2}, \mathrm{DRD}_{3}$, and $\mathrm{DRD}_{5}$ immunoreactive cell bodies of Purkinje neurons have been observed (Table 2; Figure 2; Camps et al., 1990; Bouthenet et al., 1991; Ricci et al., 1995a,b; Khan et al., 1998; Lazarov et al., 1998; Barili et al., 2000; Kim et al., 2009; Flace et al., 2018a, 2019a,b, 2020). In the granular layer, $\mathrm{DRD}_{2}$ immunoreactivity in the cell bodies and processes of granules, Golgi neurons (Table 2; Figure 2), and in different non-traditional large neuron types of the granular layer distributed in three zones has been detected (Flace et al., 2004; Flace, 2017, 2019b, 2020) such as the Lugaro neuron, candelabrum neuron, and perivascular 
neuron in the external zone of the layer, the triangular neuron in the intermediate zone, the ellipsoidal neuron, and the globular neuron in the internal zone has been detected (Table 2; data not showed; Flace et al., 2004; Ambrosi et al., 2007; Flace, 2017, 2019b, 2020). In addition, $\mathrm{DRD}_{1}, \mathrm{DRD}_{2}$, and $\mathrm{DRD}_{4}$ immunoreactive clusters in the neuropil of the granular layer have been found (Table 2; Figure 2), and $\mathrm{DRD}_{2}$ and $\mathrm{DRD}_{5}$ immunoreactivity in cell bodies of granules has been observed (Table 2; data not showed; Camps et al., 1990; Brouwer et al., 1992; Ricci et al., 1995a,b; Khan et al., 1998; Lazarov et al., 1998; Barili et al., 2000; Kim et al., 2009; Flace, 2017, 2019b; Flace et al., 2018a, 2019b, 2020). Furthermore, among immunonegative granules, the $\mathrm{DRD}_{2}$ immunoreactivity in form of clusters in the space of Held, the sites of the cerebellar glomeruli complex has been detected (Table 2; Figure 2; Flace et al., 2018a, 2019a,b, 2020).

In the mouse and human dentate nucleus, the presence of $\mathrm{DRD}_{1}$ and $\mathrm{DRD}_{2}$ immunoreactive cell bodies and processes of different large projective neuron types and small associative neuron types has been demonstrated (Table 2; Figure 4); the $\mathrm{DRD}_{2}$ immunoreactivity has also been observed in form of fine clusters in the neuropil of the dentate nucleus (Table 2; Figure 4; Flace, 2017; Flace et al., 2018a, 2019a,b, 2020; Locke et al., 2018).

In chemical neuroanatomy studies carried out on the cerebellum by means of antisera directed against the $\mathrm{TH}$, the rate-limiting enzyme of DA biosynthesis and the presence of numerous $\mathrm{TH}$ immunoreactive fibers in the various lobules and laminae of the cerebellar cortex as well as in the deep cerebellar nuclei have been demonstrated (Austin et al., 1992; Ikai et al., 1992; Takada et al., 1993, Nelson et al., 1997). In addition, regarding the $\mathrm{TH}$ immunoreactivity, it should be indicated that it is related to the presence of NA or DA, or both, since by carrying out a selective depletion of NA, most of the immunoreactivity is abolished (Fuxe, 1965; Hökfelt and Fuxe, 1969; Bloom et al., 1971). Moreover, using biochemical techniques, low levels of DA were found in the cerebellum (Carlsson, 1959; Glowinski and Iversen, 1966; Landis and Bloom, 1975). In addition, using antisera against $\mathrm{DBH}$, the enzyme responsible for the biosynthesis of NA, highlights the presence of fibers in the cerebellum, which presented only partial similarity to those observed in studies using directed antisera against DA (Verney et al., 1988; Panagopoulos et al., 1991). Furthermore, more recent studies in the cerebellum of various mammals species and in other regions of the central nervous system (CNS), demonstrated which distribution patterns of $\mathrm{TH}$ immuroreactivity were mainly correlated to catecholaminergic and not electively to the dopaminergic neurotransmission but did not exclude it; (Fallon and Moore, 1978; Hökfelt et al., 1984; Asan, 1993; Takada et al., 1993; Nelson et al., 1997). On the contrary, studies that electively used antisera against DAT evaluate specifically the distribution patterns related to dopaminergic neurotransmission (Melchitzky and Lewis, 2000; Delis et al., 2008; Flace et al., 2018a, 2019b, 2020). In addition, the DAT immunohistochemial studies evidenced the presence of a specific subpopulation of dopaminergic neuronal cell bodies and processes in the cerebellum (Melchitzky and Lewis, 2000; Delis et al., 2008; Flace et al., 2018a, 2019b, 2020), which is in

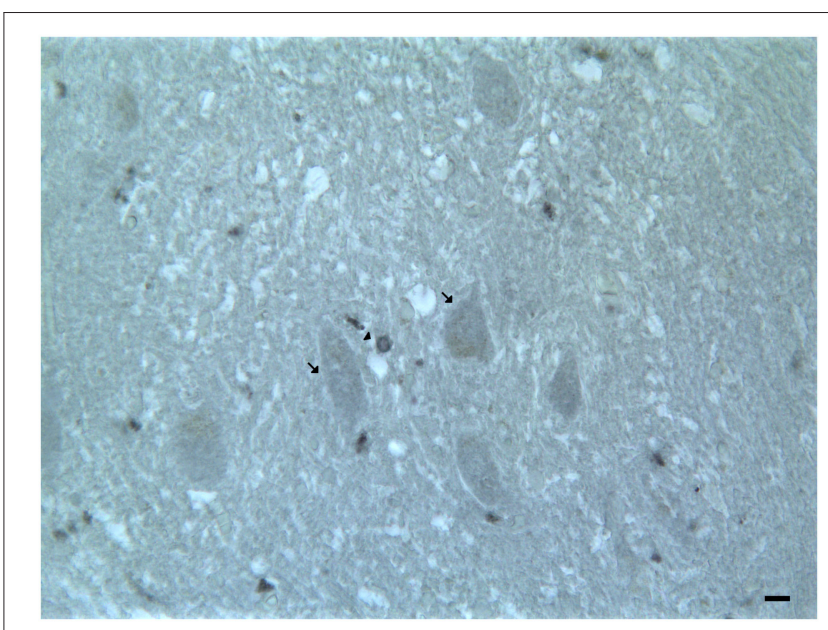

FIGURE 4 | Dopamine receptor type $2\left(\mathrm{DRD}_{2}\right)$ immunoreactivity in the dentate nucleus. The $\left(\mathrm{DRD}_{2}\right)$ immunoreactivity is detectable in the dentate nucleus gray substance and in the neighboring withe substance; $\mathrm{DRD}_{2}$ immunoreactive small neuron cell bodies (arrowheads); $\mathrm{DRD}_{2}$ immunoreactive cell body of projective neuron type, central neuron (arrow); diffuse DAT immunoreactivity in the neuropil of the nucleus (Scale bar: $15 \mu \mathrm{m}$ ).

agreement with the studies on the distribution pattern of the dopaminergic receptors subtype in the cerebellar neuronal cell bodies and processes (Martres et al., 1985; Camps et al., 1990; Mengod et al., 1992; Ricci et al., 1996; Vessotskie et al., 1997; Levant, 1998; Barili et al., 2000; Khan et al., 2000; Delis et al., 2004; Kim et al., 2009; Flace et al., 2018a, 2019a,b, 2020).

In fact, the relationship of these data suggest the existence in the cerebellum of detailed dopaminergic neurotransmitter mechanisms. For example, in terms of the distribution pattern of the DAT immunoreactivity (Melchitzky and Lewis, 2000; Delis et al., 2008; Flace et al., 2018a, 2019b, 2020) and of the dopaminergic D1-like and D2-like subtype receptors immunoreactivity (Camps et al., 1990; Bouthenet et al., 1991; Ricci et al., 1995a,b; Khan et al., 1998; Lazarov et al., 1998; Barili et al., 2000; Kim et al., 2009; Flace et al., 2018a, 2019a,b, 2020), both were expressed in the Purkinje neurons cell bodies, dendritic arborizations, and axons, and this suggests the existence of a detailed cerebellar modulation by means of dopaminergic neurotransmission mechanisms in intrinsic and extrinsic cerebellar circuits.

\section{PHYSIOLOGICAL ASPECTS ON THE DOPAMINERGIC CEREBELLAR SYSTEM}

In animal model studies, it has been indirectly demonstrated an active role of DA in the cerebellum; indeed, the administration of lacosamide and morphine in a hypoglycemic animal model decreased the cerebellar level of dopamine significantly (Guzman et al., 2014). In the cerebellum of albino rats, the long administration of morphine sulfate determines a decrease in the levels of DA and histopathological changes (Bekheet et al., 2010). Hypoxic conditions induced in the cerebellum of neonatal rats a decrease in the DA levels and a reduced expression of 
the dopaminergic subtype receptors $\mathrm{DRD}_{1}$ and $\mathrm{DRD}_{2}$; these decreases are in part reversed by the supplementation of glucose, oxygen, and adrenaline (Joseph et al., 2010). Moreover, in the cerebellum of rodents, high levels of DA have been involved in neuronal synaptic mechanisms characterized by DA release and uptake (Efthimiopoulos et al., 1991; Dethy et al., 1997). In addition, in mouse cerebellar slices, the presence of a high-affinity $\mathrm{Na}^{+}$-dependent DA uptake system has been demonstrated, and this has been characterized by a $\mathrm{K}^{+}$-induced, $\mathrm{Ca}^{+2}$-dependent dopamine release mechanism (Efthimiopoulos et al., 1991). Moreover, in several studies, it has been demonstrated in striatal medium spiny neurons a direct influence of DA in the mechanism of structural plasticity of dendritic spines (Yagishita et al., 2014). In the rat cerebellum, DA may influence in the Purkinje neurons the induction of RP a form of longlasting synaptic plasticity at inhibitory synapses by means of the cAMP-regulated protein DARPP-32 highly expressed in Purkinje neurons and involved in dopaminergic neuronal synaptic signaling (Alder and Barbas, 1995; Kawaguchi and Hirano, 2002).

Moreover, in rat Purkinje neurons dendrites, a release of DA from vesicular extrasynaptic and postsynaptic sites resulted in dopaminergic receptors paracrine and autocrine activation (volume transmission), which produced a DepolarizationInduced Slow Current (DISC; Kim et al., 2009). Moreover, in pharmacological experiments a close functional relationship in dopaminergic Purkinje neurons between DA signaling and DISC has been demonstrated; in fact, it was blocked by dopaminergic receptor antagonist (e.g., clozapine, haloperidol, and eticlopride), $\mathrm{VMAT}_{2}$ inhibitors (reserpine and tetrabenazine), and dopamine reuptake inhibitors (e.g., rimcazole; Kim et al., 2009). Furthermore, it has been suggested in recent studies which $\mathrm{TH}$ immunoreactive Purkinje neurons and $\mathrm{DRD}_{1}$ immunoreactive large projective neuron types of the dentate nucleus may be involved in the modulation of cerebellar cognitive functions (Locke et al., 2018, 2020). The selective chemogenetic inhibition of the $\mathrm{DRD}_{1}$ immunoreactive neuron type of the dentate nucleus could be involved in the impairment of cognitive functions such as spatial navigation memory, working memory, and pre-pulse inhibition of the acoustic startle reflex (Locke et al., 2018). In mice, a selective reduction of $\mathrm{TH}$ immunoreactive cerebellar Purkinje neurons has been correlated to a specific impairment of cognitive functions, such as behavioral flexibility, response inhibition, social recognition memory (Locke et al., 2020).

From the analysis of these experimental physiological and pharmacological studies, a potential role of the neuronal dopaminergic system at the cerebellar level emerges, especially in the synaptic and extrasynaptic neurotransmission and neuromodulation mechanisms (Efthimiopoulos et al., 1991; Dethy et al., 1997; Kawaguchi and Hirano, 2002; Kim et al., 2009) and, in cognitive functions related to the cerebellar activity (Locke et al., 2018, 2020). Overall, they deserve further evaluation in order to better understand the relevance of the morphofunctional role played by the dopaminergic innervation in the cerebellum and their role in the behavioral functions of the cerebellum.

\section{CEREBELLAR-MIDBRAIN DOPAMINERGIC PATHWAYS}

In rodents, lesional and axonal tracing studies has been demonstrated that the cerebellar extrinsic dopaminergic fibers originate from the midbrain dopaminergic cell groups $\left(A_{8}-A_{10}\right)$, which mainly consist of the ventral tegmental area (VTA) $\left(\mathrm{A}_{10}\right)$ and to lesser extent by the retrorubral nucleus $\left(\mathrm{A}_{8}\right)$ and the pars compacta of the substantia nigra (SNpc) ( $\mathrm{A}_{9}$; Dahlström and Fuxe, 1964; Kizer et al., 1976; Chan-Palay, 1977; Oades and Halliday, 1987; Ikai et al., 1992; Melchitzky and Lewis, 2000; Kim et al., 2009).

In addition, in cat and in rat, a direct cerebellar influence on the midbrain dopaminergic nuclei $\left(\mathrm{A}_{8}-\mathrm{A}_{10}\right)$ has been demonstrated. Fibers from the vermian cerebellar cortex and from the fastigial nucleus reach the ipsilateral VTA, whilst fibers from the interpositus and dentate nuclei reach the contralateral dorsal VTA and the medial and dorsal SNpc; moreover, 20\% of the fibers had bilateral interconnections (Figure 9; Snider and Maiti, 1976).

In the rat cerebellum, using horseradish peroxidase (HRP) anterograde and retrograde transport methods, the efferents of the dentate and interpositus nuclei to the contralateral midbrain dopaminergic cell groups $\mathrm{A}_{8}-\mathrm{A}_{10}$ have been demonstrated (Figure 9; Perciavalle et al., 2013).

Electrical stimulation of cat cerebellar dentate nucleus influenced the dopaminergic activity of the ipsilateral SNpc, which in turn increased the release of $\left[{ }^{3} \mathrm{H}\right]-\mathrm{DA}$ in the contralateral caudate nucleus and decreasing such release in the ipsilateral caudate nucleus. Moreover, the electrical stimulation of the fastigial nucleus increased only the release of $\left[{ }^{3} \mathrm{H}\right]-\mathrm{DA}$ in the ipsilateral caudate nucleus (Nieoullon et al., 1978), and the electrical stimulation of the posterior interpositus nucleus increased the release of $\left[{ }^{3} \mathrm{H}\right]-\mathrm{DA}$ in ipsilateral $\mathrm{SNpc}$ and in the contralateral caudate nucleus while decreasing the release $\left[{ }^{3} \mathrm{H}\right]-$ DA in the ipsilateral caudate nucleus (Nieoullon and Dusticier, 1980). In addition, the electrical stimulation of the mouse cerebellar dentate nucleus was elicited mainly in the contralateral nucleus accumbens (NAc), determining an asymmetrical and lateralized DA release (Figure 9; Holloway et al., 2019).

Moreover, in the last decades, the developments in neuroscience research of non-invasive and in vivo diffusion Magnetic Resonance Imaging and tractography have been increasingly used for the neuroanatomical reconstruction of putative white substance tracts or links of the human brain (Jeurissen et al., 2014; Cacciola et al., 2016a,b, 2017a,b, 2019). Although relatively few studies focused on the connectivity of midbrain nuclei, some of these reported structural connectivities between dopaminergic midbrain regions and the cerebellum (Bareš et al., 2015; Milardi et al., 2016; Cacciola et al., 2017a; Flace et al., 2017, 2018a,b, 2019a, 2020). An early work based on diffusion tensor imaging (DTI) and deterministic tractography aimed at the reconstruction of the median forebrain bundle (MFB), which represents the main white substance pathway connecting VTA and SNpc to the prefrontal cortex (PFC), found also a descending branch reaching to the cerebellum and in particular to the dentate nucleus through the superior cerebellar 

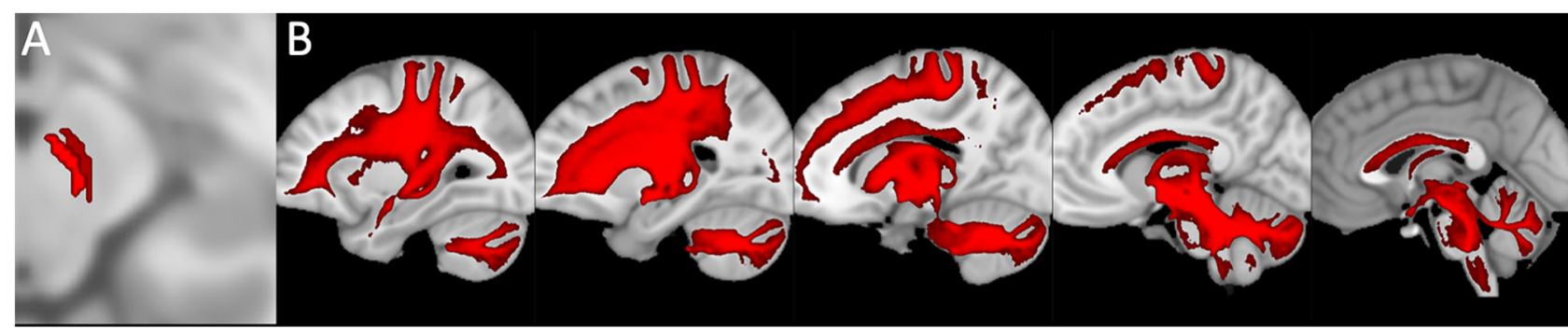

FIGURE 5 | Structural connectivity of SNpc and VTA, including putative midbrain-cerebellar connectivity. Data were obtained from the 100-unrelated-subjects sample of the HCP repository (see Van Essen et al., 2013) Diffusion datasets were processed using a multi-shell, multi-tissue constrained spherical deconvolution (MSMT-CSD) algorithm (see Jeurissen et al., 2014). A number of 10,000 streamlines passing through the left SNpc (dark red) and VTA (light red) regions of interest (see Pauli et al., 2018) (A) was generated. Streamlines were mapped to structural scans, transformed to MNI152 standard space, binarized, and summed up to obtain tract maximum probability maps (MPMs). A threshold of $50 \%$ was applied to show only tracts overlapping in at least half of the sample (B). Tractography was run on 30 high-quality 3 T structural and diffusion data from the Human Connectome Project (HCP). Data were downloaded in a minimally pre-processed form and elaborated using the signal processing technique known as Constrained Spherical Deconvolution (CSD). Regions of interest (ROI) were delineated by means of multi-atlas automated segmentation: Substantia nigra (SN) and Ventro Tegmental Area (VTA) were resliced into subject space from Adcock's probabilistic atlas; dentate nucleus (both dorsal and ventral part) using the deep cerebellar nuclei atlas featured in SPM Anatomy Tract colors are attributed according to the spatial orientation of streamlines: superior-inferior (blue), anterior-posterior (green), and latero-lateral (red).

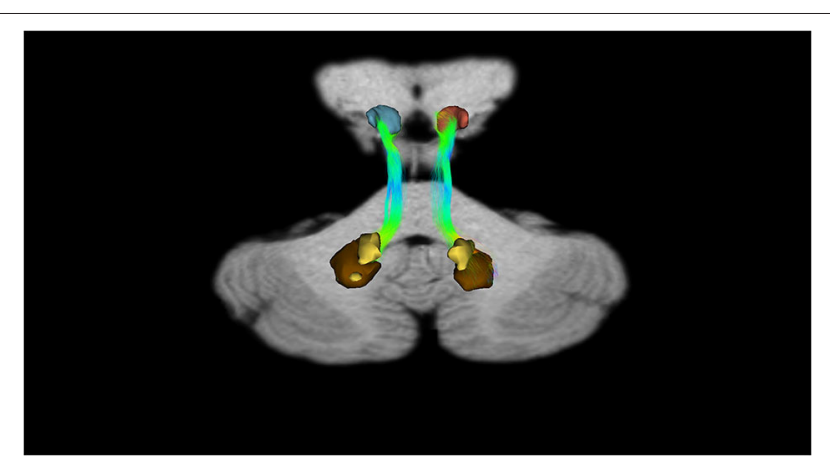

FIGURE 6 | Dentate-nigral interconnections. Coronal view shows the interconnections between the right dentate nucleus and the ipsilateral SN, and the left dentate nucleus and the ipsilateral SN. The fibers exited the cerebellum via the right and left superior cerebellar peduncles. peduncle (SCP; Coenen et al., 2012). These findings have been replicated in a study by using more advanced signal modeling algorithms and different tracking strategies (Coenen et al., 2018). Nevertheless, results coming from diffusion imaging should be interpreted with care due to the well-known limitations of the tractographic approach, such as the inability to detect axons or synapses and, then, to rule out the precise termination of putative white substance tracts at a cellular level as well as to distinguish between direct or indirect connectivity patterns and passing-by fibers (Jbabdi and Johansen-Berg, 2011). In particular, the inherently low spatial resolution of diffusion-weighted MRI makes it difficult to distinguish between SNpc, SNpr, and VTA, as their precise boundaries are not readily identifiable on conventional MRI scans (Chowdhury et al., 2013; Trutti et al., 2019). In addition, these results may be affected by passing-by fibers from the dento-rubro-thalamic tract (DRTT), which lies in close proximity to midbrain dopaminergic structures, despite

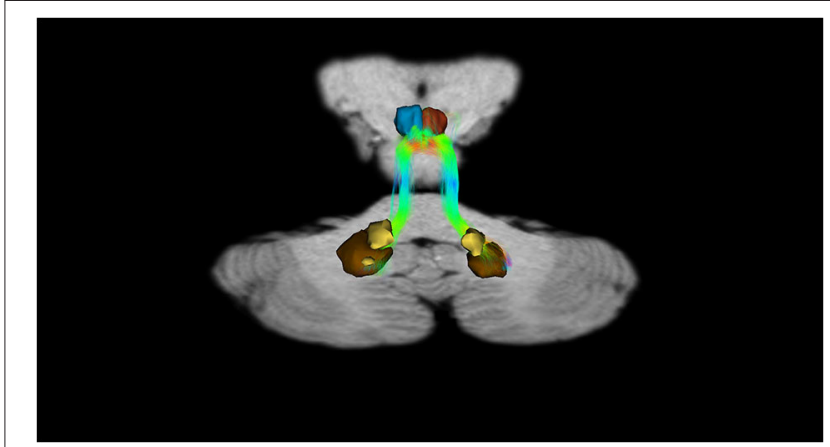

FIGURE 7 | Dentate-VTA interconnections. Coronal view shows the interconnections between the right dentate nucleus and the ipsilateral and contralateral VTA, and the left dentate nucleus and the ipsilateral and contralateral VTA. The fibers exited the cerebellum via the right and left superior cerebellar peduncles.

a recent study having suggested the potential dissociability of the cerebellar branch of MFB from DRTT (Hosp et al., 2019). In addition, in a human brain structural connectivity tractographic reconstruction of SNpc and VTA, we evidenced the existence of wide interconnections of the cerebellum with the SNpc and also with the VTA (Figure 5).

In addition, recently, by means of Constrained Spherical Deconvolution tractography (CSDt), Milardi et al. (2016) carried out a detailed analysis of direct links between the ventral and dorsal dentate nucleus and the ipsilateral SNpc (Figures 6, 8; Milardi et al., 2016). Subsequently, by means of CSDt, the existence of direct interconnections between the ventral and dorsal dentate nucleus and ipsilateral and contralateral VTA, predominantly characterized by an ipsilateral dentate-VTA links, has also been demonstrated (Figures 7, 8; Bareš et al., 2015; Milardi et al., 2016; Cacciola et al., 2017a; Flace et al., 2017, 2018a,b, 2019b, 2020). 


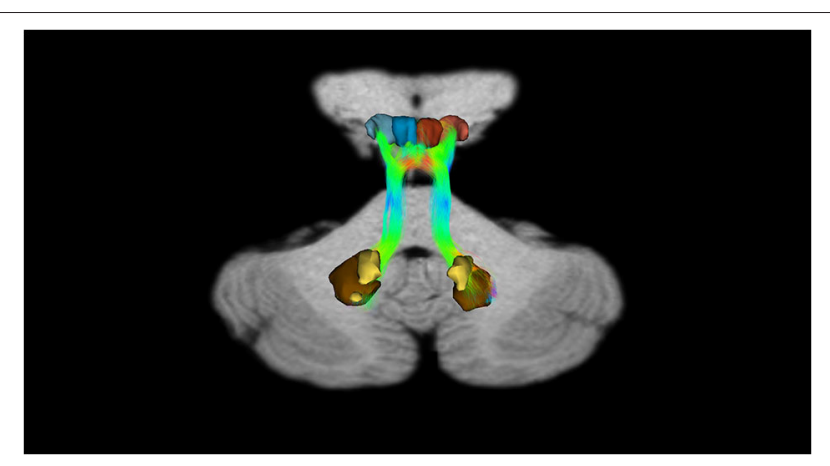

FIGURE 8 | Dentate-SN and dentate-VTA interconnections. Coronal view shows the interconnections between the right dentate nucleus and left dentate nucleus to the ipsilateral SN, between the right dentate nucleus and left dentate nucleus to the ipsilateral and contralateral VTA. The fibers exited the cerebellum via the right and left superior cerebellar peduncles.

The interconnection studies conducted with invasive methods in non-human mammals, and the analyses carried out in humans by means of tractographic neuroimaging methods highlight the presence of relevant interconnections of the cerebellum with the traditional dopaminergic areas of the brain. Moreover, this may likely suggest double direct functional DA interactions between the cerebellar dopaminergic system described in this review and the traditional DA cell groups system of the CNS (Figure 9; Björklund and Dunnett, 2007). In addition, these cerebellarmidbrain dopaminergic interconnections could represent part of the cerebellar projective circuits which allow the cerebellum to contribute to motor and cognitive functions (Koziol et al., 2014; Caligiore et al., 2017).

\section{THE ROLE OF THE DOPAMINERGIC CEREBELLAR SYSTEM IN NEUROLOGIC AND PSYCHIATRIC DISORDERS}

Though several studies suggested an involvement of the cerebellum in dopaminergic related neurologic and psychiatric disorders as PD (Jellinger, 1999, 2017; Lewis et al., 2013; Wu and Hallett, 2013), SCZ (Andreasen and Pierson, 2008; O'Hallaran et al., 2012; Parker et al., 2014), and ASD (O'Hallaran et al., 2012; Hampson and Blatt, 2015; Phillips et al., 2015), the precise role of the cerebellar dopaminergic system has not been fully characterized yet.

In this review, briefly, we analyzed some considerable experimental and clinical aspects of the cerebellum related to the dopaminergic system and its disorders.

Currently, only in few detailed studies has the direct involvement of a dopaminergic system at the cerebellar level in PD been analyzed. In a 6-hydroxydopamine (6-OHDA) animal model, increases in the DA level and its metabolites in the anterior cerebellum and as well as a decrease in the caudateputamen have been detected (Kolasiewicz et al., 2012). In the cerebellum of PD patients, a reduced mRNA expression of TH and of some dopaminergic receptor subtypes $\left(\mathrm{DRD}_{1}-\mathrm{DRD}_{3}\right)$ has been found (Hurley et al., 2003). In a human PD postmortem brain study it was shown that in the Purkinje neurons, a high expression of the calpain II (calpastatin), a calcium-dependent protease, resulted in overexpression in the dopaminergic neurons of SNpc (Mouatt-Prigent et al., 2000). PTEN-induced putative kinase 1 (PINK1) mutations related to the recessive genetic forms of parkinsonism, in the cerebellum of PD patients in Purkinje neuron and in several neuron types of dentate nuclei have been detected (Blackinton et al., 2007; Dodson and Guon, 2007).

The deposition of cerebellar $\alpha$-synuclein ( $\alpha-S)$ during PD remains unclear (Takahashi and Wakabayashi, 2001; Kingsbury et al., 2004). Indeed, some studies evidenced the presence of decreased or unchanged levels of $\alpha$-S in the cerebellum (Tan et al., 2005; Westerlund et al., 2008), while others demonstrated a high mRNA expression of the $\alpha$-S gene (SNCA) in the human cerebellum (Fuchs et al., 2008). Moreover, in the cerebellum of PD patients and of [A30P] transgenic mouse as well as in $\alpha-S$ in the molecular layer, the Bergmann glia (Mori et al., 2003; Piao et al., 2003), in the Purkinje neurons, in the space of Held of the granular layer, in the neuropil and in cell bodies and processes of different neuron types of the dentate nucleus has been found (Kahle et al., 2000; Mori et al., 2003). Furthermore, an $\alpha$-S neuroprotective activity in cerebellar granules against neurotoxicity of 6-OHDA has been also demonstrated (Monti et al., 2007).

In rat cerebellum, high mRNA expression of clusterin/apolipoprotein J, a glycoprotein involved in the regulation of $\alpha$-S deposition (Sasaki et al., 2002; Emamzadeh, 2017) in the Purkinje neurons as well as in the neurons of the fastigial and interpositus nuclei, has been detected (Pasinetti et al., 1994).

Currently, no studies are available on the direct involvement of the cerebellar dopaminergic system in SCZ and in autism ASD. However, in several studies, the presence of cerebellar abnormalities in SCZ and ASD patients has been demonstrated. In SCZ, patterns of atrophy in the cerebellar cortex of the vermis have been demonstrated (Weinberger et al., 1980; Reyes and Gordon, 1981; Heath et al., 1982; Snider, 1982; Martin and Albers, 1995). In addition, reduced cerebellar cortical volumes (Laidi et al., 2015), a decreased cerebellar gray substance of Crus I and II ansiform lobules (Kühn et al., 2012), and a reduction in the gyrification index in the cerebellar vermis have also been observed (Schmitt et al., 2011). Moreover, in the cerebellum of SCZ patients, in a microscopical analysis, a loss or a reduced cell size of the Purkinje neurons has been revealed (Stevens, 1982; Tran et al., 1998). Furthermore, a reduced cerebellar expression of the $\mathrm{Sp}$ transcription factors and $\mathrm{DRD}_{2}$, both related to negative symptoms of SCZ, has been found (Pinacho et al., 2013).

In ASD morphological studies, in the cerebellar hemispheres a reduction of the number of the Purkinje neurons related to a reduction of the Nissl staining has been demonstrated (Bauman and Kemper, 1985; Kemper and Bauman, 1993). Furthermore, in the cerebellum of ASD patients, we also found a reduced Purkinje neuron density (Whitney et al., 2008; Skefos et al., 2014) together 


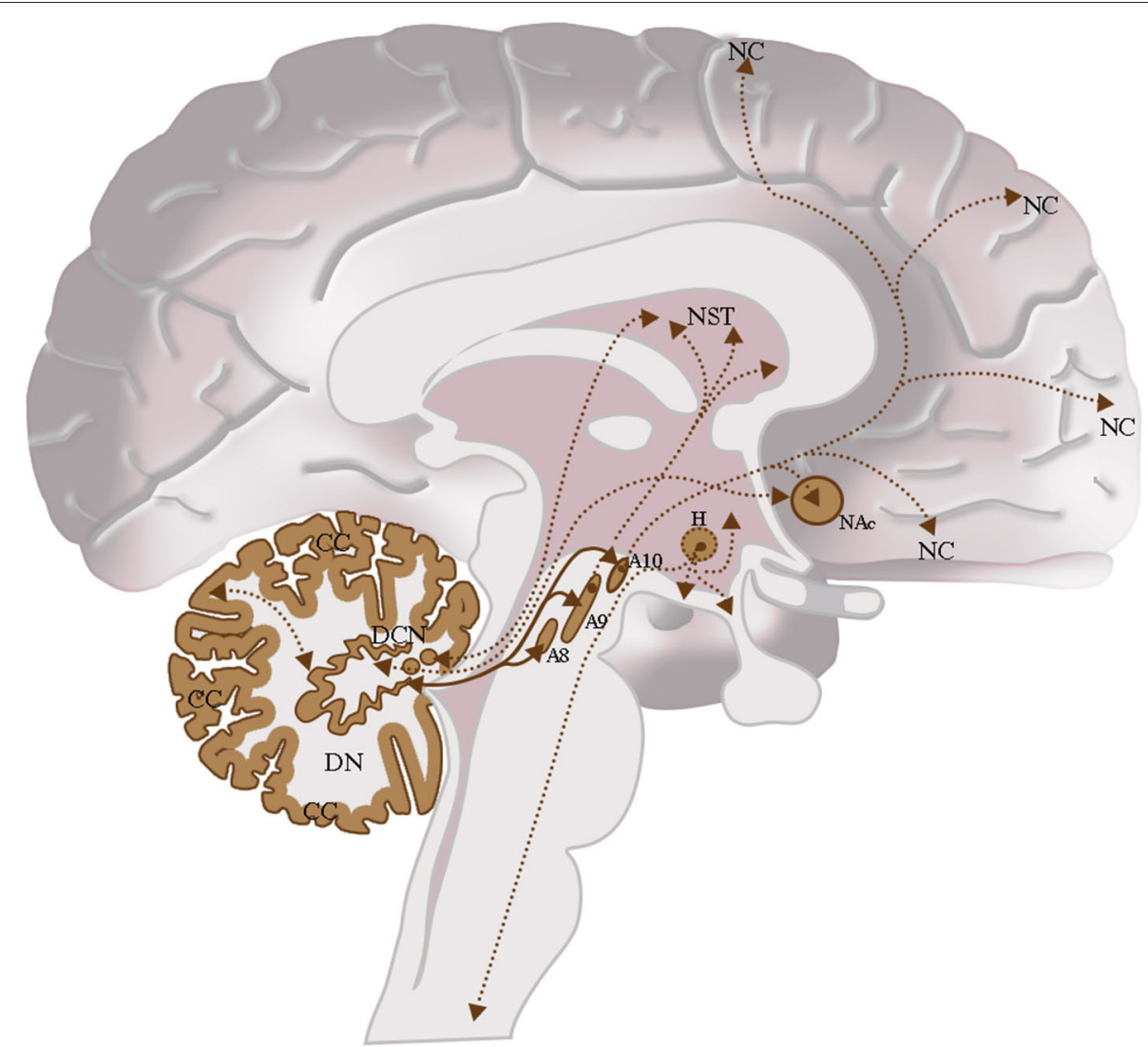

FIGURE 9 | The dopaminergic CNS and their interconnections. Cerebellum: Cerebellar Cortex (CC), Deep Cerebellar Nuclei (DCN); Midbrain: Retrorubral Nucleus $\left(A_{8}\right)$, Substantia Nigra Pars Compacta $\left(A_{9}\right)$, Ventral Tegmental Area $\left(A_{10}\right)$; Hypothalamus (H); Nucleus Accumbens (NAc); Neostriatum (NST); Neocortex (NC). Intrinsic cerebellar dopaminergic interconnections: Between the dentate nucleus (DN) and the cerebellar cortex (CC); these interconnections are indicated in brown with the double arrow and the bold line. Extrinsic cerebellar dopaminergic interconnections: Between the dentate nucleus (DN) and the nuclei of the midbrain $A_{8}, A_{9}$, and $A_{10}$; interconnections are indicated in brown with a double arrow and bold line. Between the dentate nucleus (DN) and the Neostriatum (NST); among others Deep Cerebellar Nuclei Nuclei (DCN) and the NST or the NAc. These interconnections are indicated in brown with the double arrow and the thin dashed line. Other Dopaminergic Interconnections of the CNS: Interconnection between the Ventral Tegmental Area $\left(A_{10}\right)$ and the NAc or between the Ventral Tegmental Area $\left(A_{10}\right)$ and the Neocortex (NC). These interconnections are indicated in brown with the double arrow and the thin dashed line.

with the decreased cell body size of the Purkinje neuron (Fatemi et al., 2002).

Moreover, studies suggested that SCZ and ASD symptoms, in part, may be derived from abnormalities of cerebro-cerebellar interconnections (Andreasen et al., 1998; Strick et al., 2009; Mosconi et al., 2015).

Furthermore, electrical stimulations of the Purkinje neuron layer and of the dentate nucleus evokes a long-lasting increase of DA efflux in the PFC, and this suggests a possible disconnection between the Purkinje neurons and neuronal population of the dentate nucleus, which in turn can lead to aberrant DA signaling in the PFC and to abnormal behavior related to symptoms of SCZ and ASD (Mittleman et al., 2008; Rogers et al., 2013).

Therefore, the cerebellum and its dopaminergic innervation and their interconnections to the other midbrain dopaminergic areas suggested a direct cerebellar involvement in the PD pathophysiological mechanisms (Lewis et al., 2013; Wu and Hallett, 2013; Yoo et al., 2019). Furthermore, the relevant role of the cerebellum is also strongly indicated in psychiatric disorders such as SCZ and ASD characterized by a significant dysregulation of the dopaminergic system (Andreasen et al., 1998; Strick et al., 2009; Mosconi et al., 2015).

\section{THE ROLE OF THE DOPAMINERGIC CEREBELLAR SYSTEM IN THE TREATMENT OF NEUROLOGIC AND PSYCHIATRIC DOPAMINE-RELATED DISORDERS}

Taken together, the data evidenced in the present review, suggested the existence of a cerebellar dopaminergic neuronal system, which can be the target for pharmacological, nonpharmacological, or combined therapeutic treatments (Miterko et al., 2019); here, we will briefly review some of the therapeutic aspects on the cerebellar dopaminergic system in PD, SCZ, and ASD. 
In $\mathrm{PD}$, neuroimaging studies have demonstrated L-DOPA administration resulted involved in asymmetrical effects in motor brain regions, highlighting differences in cerebellar activity (Martinu et al., 2014). In PD patients, an increased putamencerebellar activity after abstention of L-DOPA administration has been proven, suggesting a role for the cerebellum in compensatory mechanisms (Simioni et al., 2015).

In SCZ antipsychotic treatments, the cerebellum may also represent part of the pharmacologic target. In rat cerebellum, the atypical antipsychotic blonaserin and the anxiolytic buspirone engage extensively in dopamine receptor $\mathrm{DRD}_{3}$ (Baba et al., 2015; Di Ciano et al., 2017); indeed, in the cerebellum an extensive distribution of the dopamine receptor $\mathrm{DRD}_{3}$ has been demonstrated (Barili et al., 2000; Kim et al., 2009). Furthermore, in genomic DNA isolated from the cerebellum, the atypical antipsychotic agent olanzapine increased methylation of genes related to the dopaminergic system, such as $\mathrm{DRD}_{5}$, DOPA decarboxylase (DDC8), and $\mathrm{VMAT}_{2}$ (SCL18A2/VMAT2; Melka et al., 2013).

The cerebellum is extensively interconnected to the other brain regions involved in motor, cognitive, and affective functions (Milardi et al., 2016; Cacciola et al., 2017a, 2019; Caligiore et al., 2017; Bostan and Strick, 2018; Flace et al., 2018b). Although, these cerebellar interconnections have not yet been fully characterized, in studies, it has been demonstrated that the cerebellum may represent the ideal target of noninvasive brain stimulation therapies such as electrical or magnetic stimulations applied in therapies for neurological and psychiatric disorders (van Dun et al., 2017; Miterko et al., 2019; Quartarone et al., 2020). In PD patients, bilateral cerebellar repetitive Transcranial Magnetic Stimulation (rTMS) induced persistent clinical beneficial effects, reducing peak-dose L-DOPA-induced dyskinesia (Koch, 2010).

In healthy subjects, cerebellar vermal theta burst stimulation (TBS) produced downstream changes in neuronal activity in the frontal cortex (Schutter et al., 2003), and pharmacological treatment-resistant SCZ patients can improved cognitive functions (Demirtas-Tatlidede et al., 2010). The rTMS In ASD has been used to study excitatory/inhibitory imbalance (Uzunova et al., 2016) and can represent an innovative therapeutic approach for reducing some of the core and associated ASD symptoms (Oberman et al., 2016).

\section{DISCUSSION AND CONCLUSION}

The present review extensively evidenced the available morphological, chemical, and functional data on the existence of a cerebellar dopaminergic system in mammals including humans, which consist of extrinsic fibers which originate mainly from the midbrain cerebellar dopaminergic nuclei $\left(\mathrm{A}_{8}-\mathrm{A}_{10}\right.$; Ikai et al., 1992; Nelson et al., 1997) and of intrinsic dopaminergic neuronal subpopulations mainly composed of cortico-cerebellar projective neuron types, such as the Purkinje neuron and the synarmotic neuron, and by different cerebello-nuclear neuron types (Nelson et al., 1997; Delis et al., 2008; Flace, 2017; Flace et al., 2018a, 2019b).

In addition, this review evidenced the presence of direct dentate-SNpc and dentate-VTA interconnections (Milardi et al., 2016; Flace et al., 2017, 2018a, 2019b, 2020), which may play a relevant modulatory role in DA release at the PFC (Mittleman et al., 2008; Rogers et al., 2013) and highlight the possible involvement of dopaminergic cerebellar circuits in dopaminergic related disorders such as PD (Wu and Hallett, 2013; Flace et al., 2018a, 2019b, 2020), SCZ (Martin and Albers, 1995; Mittleman et al., 2008; Rogers et al., 2013; Parker et al., 2014), and ASD (Kemper and Bauman, 1993; Mittleman et al., 2008; Rogers et al., 2013).

Finally, we suggest that the cerebellar dopaminergic system and its interconnections may represent an ideal candidate for innovative non-invasive treatments such as electrical or magnetic stimulations in neurological and psychiatric disorders (DemirtasTatlidede et al., 2010; Koch, 2010; Oberman et al., 2016; Miterko et al., 2019; Quartarone et al., 2020). These innovative therapeutic objectives constitute relevant elements of study and we hope that they can be achieved in a relatively short time.

\section{AUTHOR CONTRIBUTIONS}

PF designed the study, performed the experiments and the analysis of the experimental data, and participated in the writing of the manuscript. PL and DG shared the study project and participated in the writing of the manuscript. GB, $\mathrm{ABi}, \mathrm{SBe}$, $\mathrm{JB}, \mathrm{SBi}$, and $\mathrm{ABr}$ participated in the writing of the manuscript. GG, MG, and GA performed the analysis of the experimental data, participated in the writing of the manuscript. All authors contributed to the article and approved the submitted version.

\section{FUNDING}

We are particularly grateful to Maria Antonia Sironi and Graziano Benfenati, a person affected by Parkinson's disease; as advocates of free and independent scientific research, who have funded and permitted the publication of this review.

\section{ACKNOWLEDGMENTS}

The authors are grateful to Dr. Paola Leo for the linguistic help, Mr. Michele Piperis and Mr. Antonio Zaza for IT support, and Mr. Francesco Fumai and Mr. Raffaele Guerra for technical laboratory assistance.

\section{REFERENCES}

Adolfsson, R., Gottfries, C. G., Roos, B. E., and Windblad, B. (1979). Postmortem distribution of dopamine and homovanillic acid in human brain, variations

related to age, and review of the literature. J. Neural. Transm. 45, 81-105. doi: 10.1007/BF01250085

Alder, R., and Barbas, H. (1995). Complementary distribution of the phosphoproteins DARPP-32 and I-1 in the cerebellar system. 
Neuroreport 6, 2368-2372. doi: 10.1097/00001756-199511270-0 0022

Ambrosi, G., Flace, P., Lorusso, L., Girolamo, F., Rizzi, A., Bosco, L., et al. (2007). Non-traditional large neuron in the granular layer of the cerebellar cortex. Eur. J. Histochem. 51(Suppl 1), 59-64.

Andreasen, N. C., Paradiso, S., and O'Leary, D. S. (1998). “Cognitive dysmetria" as an integrative theory of schizophrenia: a corticalsubcortical-cerebellar circuitry? Schizophr. Bull. 24, 203-218. doi: 10.1093/oxfordjournals.schbul.a033321

Andreasen, N. C., and Pierson, R. (2008). The role of the cerebellum in schizophrenia. Biol. Psychiatry 64, 81-88. doi: 10.1016/j.biopsych.2008.01.003

Ankri, L., Husson, Z., Pietrajtis, K., Proville, R., Léna, C., Yarom, Y., et al. (2015). A novel inhibitory nucleo-cortical circuit controls cerebellar Golgi cell activity. Eife 4:e062262. doi: 10.7554/eLife.06262

Asan, E. (1993). Comparative single and double immunolabelling with antisera against catecholamine biosynthetic enzymes: criteria for the identification of dopaminergic, noradrenergic and adrenergic structures in selected rat brain areas. Histochemistry 99, 427-442. doi: 10.1007/BF00274095

Austin, M. C., Schultzberg, M., Abbott, L. C., Montpied, P., Evers, J. R., Paul, S. M., et al. (1992). Expression of tyrosine hydroxylase in cerebellar Purkinje neurons of the mutant tottering and leaner mouse. Mol. Brain Res. 15, 227-240. doi: 10.1016/0169-328X(92)90113-P

Baba, S., Enomoto, T., Horisawa, T., Hashimoto, T., and Ono, M. (2015). Blonanserin extensively occupies rat dopamine D3 receptors at antipsychotic dose range. J. Pharmacol. Sci. 127, 326-331. doi: 10.1016/j.jphs.2015.01.007

Bareš, M., Apps, R., Kikinis, Z., Timmann, D., Oz, G., Ashe, J. J., et al. (2015). Proceedings of the workshop on cerebellum, basal ganglia and cortical connections unmasked in health and disorder held in Brno, Czech Republic, October $17^{\text {th }}, 2013$. Cerebellum 14, 142-150. doi: 10.1007/s12311-014-0595-y

Barili, P., Bronzetti, E., Ricci, A., Zaccheo, D., and Amenta, F. (2000). Microanatomical localization of dopamine receptor protein immunoreactivity in the rat cerebellar cortex. Brain Res. 854, 130-138. doi: 10.1016/S0006-8993(99)02306-9

Batchelor, A. M., Madge, D. J., and Garthwaite, J. (1994). Synaptic activation of metabotropic glutamate receptors in the parallel fibrePurkinje cell pathway in rat cerebellar slices. Neuroscience 63, 911-915. doi: 10.1016/0306-4522(94)90558-4

Batini, C., Compoint, C., Buisseret-Delmas, C., Daniel, H., and Guegan, M. (1992). Cerebellar nuclei and the nucleocortical projections in the rat: retrograde tracing coupled to GABA and glutamate immunohistochemistry. J. Comp. Neurol. 315, 74-84. doi: 10.1002/cne.903150106

Bauman, M. L., and Kemper, T. L. (1985). Histoanatomic observations of the brain in early infantile autism. Neurology 35, 866-874. doi: 10.1212/WNL.35.6.866

Beckstead, R. M., Domesick,. V. B., and Nauta, W. J. (1979). Efferent connections of the substantia nigra and ventral tegmental area in the rat. Brain Res. 175, 191-217. doi: 10.1016/0006-8993(79)91001-1

Bekheet, S. H., Saker, S. A., Abdel-Kader, A. M., and Younis, A. E. (2010). Histopathological and biochemical changes of morphine sulphate administration on the cerebellum of albino rats. Tissue Cell 42, 165-175. doi: 10.1016/j.tice.2010.03.005

Benagiano, V., Flace, P., Lorusso, L., Rizzi, A., Bosco, L., Cagiano, R., et al. (2009). Vasoactive intestinal polypeptide immunoreactivity in the human cerebellum: qualitative and quantitative analyses. J. Anat. 215, 256-266. doi: 10.1111/j.1469-7580.2009.01110.x

Benagiano, V., Flace, P., Virgintino, D., Rizzi, A., Roncali, L., and Ambrosi, G. (2000a). Immunolocalization of glutamic acid decarboxylase in postmortem human cerebellar cortex. A light microscopy study. Histochem. Cell Biol. 114, 191-195. doi: 10.1007/s004180000180

Benagiano, V., Lorusso, L., Flace, P., Girolamo, F., Rizzi, A., Bosco, L., et al. (2011). VAMP-2, SNAP-25A/B and syntaxin1 in glutamatergic and GABAergic synapses of the rat cerebellar cortex. BMC Neurosci. 12:118. doi: 10.1186/1471-2202-1 $2-118$

Benagiano, V., Virgintino, D., Rizzi, A., Flace, P., Troccoli, V., Bormann, J., et al. (2000b). Glutamic acid decarboxylase-positive neuronal cell bodies and terminals in human cerebellar cortex. Histochem J. 32, 557-564. doi: 10.1023/A:1004106428844
Bishop, G. A., and Ho, R. H. (1985). The distribution and origin of serotonin immunoreactivity in the rat cerebellum. Brain Res. 331, 195-207. doi: 10.1016/0006-8993(85)91545-8

Bishop, G. A., Ho, R. H., and King, J. S. (1988). A temporal analysis of the origin and distribution of serotonergic afferents in the cerebellum of pouch young. Anat. Embryol. 179, 33-48. doi: 10.1007/BF00305098

Björklund, A., and Dunnett, S. B. (2007). Dopamine neuron systems in the brain: an update. Trends Neurosci. 30, 194-202. doi: 10.1016/j.tins.2007.03.006

Blackinton, J. G., Anvret, A., Beilina, A., Olson, L., Cookson, M. R., and Galte, D. (2007). Expression of PINK1 mRNA and Parkinson's disease. Brain Res. 1184, 10-16. doi: 10.1016/j.brainres.2007.09.056

Bloom, F. E., Hoffer, B. J., and Siggins, G. R. (1971). Studies on norepinephrine containing afferents to Purkinje cells of rat cerebellum. I. Localization of the fibers and their synapses. Brain Res. 25, 501-521. doi: 10.1016/0006-8993(71)90457-4

Bostan, A. C., and Strick, P. L. (2018). The basal ganglia and the cerebellum: nodes in an integrated network. Nat. Rev. Neurosci. 19, 338-350. doi: 10.1038/s41583-018-0002-7

Bouthenet, M. L., Souil, E., Martres, M. P., Sokolof, P., Giros, B., and Schwartz, J. C. (1991). Localization of dopamine D3 receptor mRNA in the rat brain using in situ hybridization histochemistry: comparison with dopamine D2 receptor mRNA. Brain Res. 564, 203-219. doi: 10.1016/0006-8993(91)91456-B

Brouwer, N., Van Dijken, H., Ruiters, M. H., Van Willigen, J. D., and Ter Horst, G. J. (1992). Localization of dopamine D2 receptor mRNA with nonradioactive in situ hybrodization histochemistry. Neurosci. Lett. 142, 223-227. doi: 10.1016/0304-3940(92)90378-K

Cacciola, A., Bertino, S., Basile, G. A., Di Mauro, D., Calamuneri, A., Chillemi, G., et al. (2019). Mapping the structural connectivity between the periaqueductal gray and the cerebellum in humans. Brain Struct. Funct. 224, 2153-2165. doi: 10.1007/s00429-019-01893-x

Cacciola, A., Calamuneri, A., Milardi, D., Mormina, E., Chillemi, G., Marino, S., et al. (2017a). A connectomic analysis of the human basal ganglia network. Front. Neuroanat. 11:85. doi: 10.3389/fnana.2017.00085

Cacciola, A., Milardi, D., Basile, G. A., Ciolli, P., Irrea, M., Cutroneo, G., et al. (2016b). A direct cortico-nigral pathway as revealed by constrained spherical deconvolution tractography in humans. Front. Hum. Neurosci. 10:374. doi: 10.3389/fnhum.2016.00374

Cacciola, A., Milardi, D., Livrea, P., Flace, P., Anastasi, G., and Quaratarone, A. (2017b). The known and missing links between the cerebellum, basal ganglia, and cerebral cortex. Cerebellum 16, 753-755. doi: 10.1007/s12311-017-0850-0

Cacciola, A., Milardi, D., and Quartarone, A. (2016a). Role of corticopallidal connectivity in the pathophysiology of dystonia. Brain 139:e48. doi: 10.1093/brain/aww102

Caligiore, D., Pezzulo, G., Baldassarre, G., Bostan, A. C., Strick, P. L., Doya, K., et al. (2017). Consensus paper: towards a systems-level view a cerebellar functions: the interplay between cerebellum, basal ganglia and cortex. Cerebellum 16, 203-229. doi: 10.1007/s12311-016-0763-3

Camps, M., Cortés, R., Gueye, B., Probst, A., and Palacios, J. M. (1989). Dopamine receptors in human brain: autoradiographic distribution of D2 sites. Neuroscience 28, 275-290. doi: 10.1016/0306-4522(89)90179-6

Camps, M., Kelly, P. H., and Palacios, J. M. (1990). Autoradiographic localization of dopamine D1 and D2 receptors in the brain of several mammalian species. J. Neural. Transm. Gen. Sect. 80, 105-127. doi: 10.1007/BF01257077

Carlsson, A. (1959). The occurrence, distribution and physiological role of catecholamines in the nervous system. Pharmacol. Rev. 11, 490-493.

Carta, I., Chen, C. H., Schott, A. L., Dorizan, S., and Khodakhah, K. (2019). Cerebellar modulation of the reward circuitry and social behavior. Science 363:6424. doi: 10.1126/science.aav0581

Chan-Palay, V. (1977). Cerebellar Dentate Nucleus. Organization, Citology and Transmitters. Berlin; Heidelberg: Springer-Verlag. doi: 10.1007/978-3-642-66498-4

Cheun, J. E., and Yeh, H. H. (1996). Noradrenergic potentiation of cerebellar Purkinje cell responses to GABA: cyclic AMP as intracellular intermediary. Neuroscience 74, 835-844. doi: 10.1016/0306-4522(96)00130-3

Chowdhury, R., Lambert, C., Dolan, R. J., and Düzel, E. (2013). Parcellation of the human substantia nigra based on anatomical connectivity to the striatum. Neuroimage 81, 191-198. doi: 10.1016/j.neuroimage.2013.05.043 
Clements, J. R., Monaghan, P. L., and Beitz, A. J. (1987). An ultrastructural description of glutamate-like immunoreactivity in the rat cerebellar cortex. Brain Res. 421, 343-348. doi: 10.1016/0006-8993(87)91304-7

Coenen, V. A., Panksepp, J., Hurwitz, T. A., Urbach, H., and Mädler, B. (2012). Human medial forebrain bundle (MFB) and anterior thalamic radiation (ATR): imaging of two major subcortical pathways and the dynamic balance of opposite affects in understanding depression. J. Neuropsychiatry Clin. Neurosci. 24, 223-236. doi: 10.1176/appi.neuropsych.11080180

Coenen, V. A., Schumacher, L. V., Kaller, C., Schlaepfer, T. E., Reinacher, P. C., Egger, K., et al. (2018). The anatomy of the human medial forebrain bundle: ventral tegmental area connections to reward-associated subcortical and frontal lobe regions. Neuroimage Clin. 18, 770-783. doi: 10.1016/j.nicl.2018.03.019

Cornea-Hébert, V., Riad, M., Wu, C., Singh, S. K., and Descarries, L. (1999). Cellular and subcellular distribution of the serotonin 5-HT2A receptor in the central nervous system of adult rat. J. Comp. Neurol. 409, 187-209. doi: 10.1002/(SICI)1096-9861(19990628)409:2andlt;187::AIDCNE2andgt;3.0.CO;2-P

Cortés, R., Gueye, B., Pazos, A., Probst, A., and Palacios, J. M. (1989). Dopamine receptors in human brain: autoradiographic distribution of D1 sites. Neuroscience 28, 263-273. doi: 10.1016/0306-4522(89)90178-4

Crivellato, E., Damiani, D., Travan, L., Marcon, G., Fusaroli, F. P., and Mallardi, F. (1992). Serotoninergic fibres form dense synaptic contacts with Purkinje cells in the mouse cerebellar cortex -an immunohistochemical study. Acta Histochem. 92, 54-60. doi: 10.1016/S0065-1281(11)80141-8

Crook, J., Hendrickson, A., and Robinson, F. R. (2006). Co-localization of glycine and gaba immunoreactivity in interneurons in Macaca monkey cerebellar cortex. Neuroscience 141, 1951-1959. doi: 10.1016/j.neuroscience.2006.05.012

Cumming-Hood, P. A., Strahlendorf, H. K., and Strahlendorf, J. C. (1993). Effects of serotonin and the 5-HT2/1C receptor agonist DOI on neurons of the cerebellar dentate/interpositus nuclei: possible involvement of GABAergic interneuron. Eur. J. Pharmacol. 236, 457-465. doi: 10.1016/0014-2999(93)90485-Z

Dahlström, A., and Fuxe, K. (1964). Evidence for the existence of monoaminecontaining neurons in the central nervous system. I. Demonstration of monoamines in the cell bodies of brainstem neurons. Acta Physiol. Scand. Suppl. 232, 1-55.

Delis, F., Mitsacos, A., and Giompres, P. (2004). Dopamine receptor and levels are altered in brain of Purkinje cell degeneration mutant mice. Neuroscience 125, 255-268. doi: 10.1016/j.neuroscience.2004.01.020

Delis, F., Mitsacos, A., and Giompres, P. (2008). Pharmacological characterization and anatomical distribution of the dopamine transporter in the mouse cerebellum. Cerebellum 7, 242-251. doi: 10.1007/s12311-008-0005-4

Demirtas-Tatlidede, A., Freitas, C., Cromer, J. R., Safar, L., Ongur, D., Stone, W. S., et al. (2010). Safety and proof of principle study of cerebellar vermal theta burst stimulation in refractory schizophrenia. Schizophr. Res. 124, 91-100. doi: 10.1016/j.schres.2010.08.015

Dethy, S., Manto, M., Bastianelli, E., Gangji, V., Laute, M. A., Goldman, S., et al. (1997). Cerebellar spongiform degeneration induced by acute lithium intoxication in the rat. Neurosci. Lett. 224, 25-28. doi: 10.1016/S0304-3940(97)13461-9

Di Ciano, P., Cormick, P. M., Stefan, C., Wong, E., Kim, A., Remington, G., et al. (2017). The effects of buspirone on occupancy of dopamine receptors and the rat gambling task. Psychopharmacology 234, 3309-3320. doi: $10.1007 / \mathrm{s} 00213-017-4715-5$

Di Mauro, M., Fretto, G., Caldera, M., Li Volsi, G., Licata, F., Ciranna, L., et al. (2003). Noradrenaline and 5-hydroxytryptamine in cerebellar nuclei of the rat: functional effects on neuronal firing. Neurosci. Lett. 347, 101-115. doi: 10.1016/S0304-3940(03)00509-3

Dietrichs, E. (1985). Divergent axon collaterals to cerebellum and amygdala from neurons in the parabrachial nucleus, the locus coeruleus and some adjacent nuclei. A fluorescent double labelling study using rhodamine labelled latex microspheres and fast blue as retrograde tracers. Anat. Embryol. 172, 375-382. doi: $10.1007 /$ BF00318986

Dietrichs, E. (1988). Cerebellar cortical and nuclear afferents from the feline locus coeruleus complex. Neuroscience 27, 77-91. doi: 10.1016/0306-4522(88)90220-5

Dieudonné, S., and Dumoulin, A. (2000). Serotonin-driven long-range inhibitory connections in the cerebellar cortex. J. Neurosci. 20, 1837-1848. doi: 10.1523/JNEUROSCI.20-05-01837.2000
Dodson, M. W., and Guon, M. (2007). Pink1, Parkin, DJ-1 and mitochondrial dysfunction in Parkinson's disease. Curr. Opin. Neurobiol. 17, 331-337. doi: 10.1016/j.conb.2007.04.010

Dunnet, S. B., Bentivoglio, M., Björklund, A., and Hökfelt, T. (2005). "Dopamine," in Handbook of Chemical Neuroanatomy, Vol. 21, eds S. B. Dunnett, M. Bentivoglio, A. Björklund, and T. Hökfelt (Amsterdam: Elsevier), 1-588.

Duxon, M. S., Flanigan, T. P., Reavley, A. C., Baxter, G. S., Blackburn, T. P., and Fone, K. C. (1997). Evidence for expression of the 5-hydroxytryptamine-2B receptor protein in the rat central nervous system. Neuroscience 76, 323-329. doi: $10.1016 /$ S0306-4522(96)00480-0

Efthimiopoulos, S., Giompres, P., and Valcana, T. (1991). Kinetics of dopamine and noradrenaline transport in synaptosomes from cerebellum, striatum and frontal cortex of normal and reeler mice. J. Neurosci. Res. 29, 510-519. doi: $10.1002 /$ jnr.490290411

Emamzadeh, F. N. (2017). Role of apolipoprotein and $\alpha$-synuclein in Parkinson's disease. J. Mol. Neurosci. 62, 344-355. doi: 10.1007/s12031-017-0942-9

Emond, P., Guilloteau, D., and Chalon, S. (2008). PEI2: a radiopharmaceutical for exploration of the dopamine transporter. CNS Neurosci. Ther. 14, 47-64. doi: 10.1111/j.1755-5949.2007.00033.x

Falck, B., and Torp, A. (1962). New evidence for the localization of noradrenalin in the adrenergic nerve terminals. Med. Exp. Int. J. Exp. Med. 6, 169-172. doi: $10.1159 / 000135153$

Fallon, J. H., and Moore, R. Y. (1978). Catecholamine innervation of the basal forebrain. IV. Topography of the dopamine projection to the basal forebrain and neostriatum. J. Comp. Neurol. 180:5455580. doi: 10.1002/cne.901800310

Fatemi, S. H., Halt, A. R., Realmuto, G., Earle, J., Kist, D. A., Thuras, P., et al. (2002). Purkinje cell size is reduced in cerebellum of patients with autism. Cell. Mol. Neurobiol. 22, 171-175. doi: 10.1023/A:1019861721160

Felten, D. L., Felten, S. Y., Perry, K. W., Fuller, R. W., Nurnberger, J. I., and Ghetti, B. (1986). Noradrenergic innervation of the cerebellar cortex in normal and in Purkinje cell degeneration mutant mice: evidence for long term survival following loss of the two major cerebellar cortical neuronal populations. Neuroscience 18, 783-793. doi: 10.1016/0306-4522(86)90099-0

Flace, P. (2017). The neglected non-traditional large neuron types in the granular layer of the cerebellar cortex: morphofunctional and neurochemical data. Ital. J. Anat. Embryol. 122(Suppl. 1):225. doi: 10.13128/IJAE-21642

Flace, P. (2018). The perivascular neuron type and the blood brain barrier. Ital. J. Anat. Embryol. 123(Suppl. 1):90.

Flace, P. (2019a). "A study of chemical neuroanatomy on the human cerebellar serotonergic neuronal subpopulations," in 18th National Congress of the Italian Society for Neuroscience (SINS). Abstr. 48/1 (Perugia).

Flace, P. (2019b). New immunohistochemical data on the non-traditional large neuron types of the granular layer of the human cerebellar cortex. Eur. J. Histochem. 63(Suppl 2):14. doi: 10.4081/ejh.2019.3052

Flace, P. (2020). Neurochemical data on the non-traditional large neuron types of the granular layer of the human cerebellar cortex. Eur. J. Histochem. 64(Suppl. 1):2. doi: 10.4081/ejh.2020.3121

Flace, P., Anastasi, G., Milardi, D., Basile, G., Quartarone, A., and Cacciola, A. (2019a). The human cerebellar dopaminergic system, its links to the midbrain dopaminergic nuclei and role in neurologic and psychiatric disease. Neurol. Sci. 40(Suppl):S262.

Flace, P., Benagiano, V., Lorusso, L., Girolamo, F., Rizzi, A., Virgintino, D., et al. (2004). Glutamic acid decarboxylase immunoreactive large neuron types in the granular layer of the human cerebellar cortex. Anat. Embryol. 208, 55-64. doi: 10.1007/s00429-003-0374-x

Flace, P., Bruschetta, D., Marino, S., Magaudda, L., Milazzo, C., Di Mauro, D., et al. (2017). Constrained spherical deconvolution tractography reveals a direct cerebello-ventro tegmental pathway in humans. Ital. J. Anat. Embryol. 122(Suppl. 1):95.

Flace, P., Cacciola, A., Milardi, D., Basile, G. A., and Anastasi, G. (2019b). Immunohistochemical and tractographic approaches on the human cerebellar dopaminergic system. Eur. J. Histochem. 63(Suppl. 2):14. doi: $10.21203 /$ rs.3.rs-30289/v1

Flace, P., Livrea, P., Galletta, D., Gulisano, M., and Gennarini, G. (2020). Translational study of the human cerebellar dopaminergic system, its interconnections and role in neurologic and psychiatric disorders. Eur. J. Histochem. 64(Suppl 3):15. doi: 10.4081/ejh.2020.3200

Flace, P., Milardi, D., Cacciola, A., and Basile, G. (2018a). Multidisciplinary morphological approaches to the intrinsic human cerebellar dopaminergic 
system, its projection and clinical role. Ital. J. Anat. Embryol. 123(Suppl. 1):91. doi: 10.13128/ijae-11395

Flace, P., Quartarone, A., Colangelo, G., Milardi, D., Cacciola, A., Rizzo, G., et al. (2018b). The neglected cerebello-limbic pathways and neuropsychological features of the cerebellum in emotion. Cerebellum 17, 243-246. doi: 10.1007/s12311-017-0884-3

Fredette, B. J., and Mugnaini, E. (1991). The GABAergic cerebello-olivary projection in the rat. Anat. Embryol. 184, 225-243. doi: 10.1007/BF01673258

Fritschy, J. M., and Grzanna, R. (1989). Immunohistochemical analysis of the neurotoxic effects of DSP-4 identifies two populations of noradrenergic axon terminals. Neuroscience 30, 181-197. doi: 10.1016/0306-4522(89)90364-3

Fuchs, J., Tichopad, A., Golub, Y., Munz, M., Schweitzer, K. J., Wolf, B., et al. (2008). Genetic variability in the SNCA gene influences alpha-synuclein levels in the blood and brain. FASEB J. 22, 1327-1334. doi: 10.1096/fj.07-9348com

Fujii, T., Sakai, M., and Nagatsu, I. (1994). Immunohistochemical demonstration of expression of tyrosine hydroxylase in cerebellar Purkinje cells of the human and mouse. Neurosci. Lett. 165, 161-163. doi: 10.1016/0304-3940(94)90734-X

Fuxe, K. (1965). The distribution of monoamine terminals in the central nervous system. Acta Physiol. Scand. Suppl. 65, 39-85. doi: 10.1007/BF00337069

Gabbott, P. L., Somogyi, J., Stewart, M. G., and Hamori, J. (1986). GABAimmunoreactive neurons in the rat cerebellum: a light and electron microscope study. J. Comp. Neurol. 251, 474-490. doi: 10.1002/cne.902510404

Gao, Z., Proietti-Onori, M., Lin, Z., Ten Brinke, M. M., Boele, H. J., Potters, J. W., et al. (2016). Excitatory cerebellar nucleocortical circuit provides internal during associative conditioning. Neuron 89, 645-657. doi: 10.1016/j.neuron.2016.01.008

Geurts, F. J., De Schutter, E., and Timmermans, J. P. (2002). Localization of 5-HT2A, 5-HT3, 5-HT5A and 5-HT7 receptor-like immunoreactivity in the rat cerebellum. J. Chem. Neuroanat. 24, 65-74. doi: 10.1016/S0891-0618(02)00020-0

Gil-Miravet, I., Melchor-Eixea, I., Arias-Sandoval, E., Vasquez-Celaya, L., Guarque-Chabrera, J., Olucha-Bordonau, F., et al. (2019). From back to front: a functional model for the cerebellar modulation in the establishment of conditioned preferences for cocaine-related cues. Addict. Biol. 26:e12834. doi: $10.1111 / \mathrm{adb} .12834$

Giompres, P., and Delis, F. (2005). Dopamine transporters in the cerebellum of mutant mice. Cerebellum 4, 105-111. doi: 10.1080/14734220510007851

Glaser, P. E., Surgener, S. P., Grondin, R., Gash, G. R., Palmer, M., Castellanos, F. $\mathrm{X}$, et al. (2006). Cerebellar neurotransmission in attention-deficit/hyperactivity disorder: does dopamine neurotransmission occur in the cerebellar vermis. J. Neurosci. Methods 151, 62-67. doi: 10.1016/j.jneumeth.2005.09.019

Glowinski, J., and Iversen, L. L. (1966). Regional studies of catecholamines in the rat brain. I. The disposition of $[3 \mathrm{H}]$ norepinephrine, $[3 \mathrm{H}]$ dopamine and $[3 \mathrm{H}]$ dopa in various regions of the brain. J. Neurochem. 13, 655-669. doi: 10.1111/j.1471-4159.1966.tb09873.x

Gottfries, C. G. (1980). Human brain levels of monoamines and their metabolites. Postmortem investigations. Acta Psychiatr. Scand. Suppl. 280, 49-61. doi: 10.1111/acps.1980.61.s280.49

Gould, T. J., Adams, C. E., and Bickford, P. C. (1997). Beta-adrenergic modulation of GABAergic inhibition in the deep cerebellar nuclei of F344 rats. Neuropharmacology 36, 75-81. doi: 10.1016/S0028-3908(96)00148-7

Grandes, P., Ortega, F., and Streit, P. (1994). Glutamate immunoreactive climbing fibres in the cerebellar cortex of the rat. Histochemistry 101, 427-437. doi: 10.1007/BF00269493

Guzman, D. C., Garcia, E. H., Mejia, G. B., Olguin, H. J., Gonzalez, J. A., and Labra Ruiz, N. A. (2014). Effect of morphine and lacosamide on levels of dopamine and 5-HIAA in brain regions of rats with induced hypoglycemia. Pak. J. Biol. Sci. J. 17, 292-296. doi: 10.3923/pjbs.2014.292.296

Hall, H., Halladin, C., Guilloteau, D., Chalon,., S., Edmond, P., et al. (1999). Visualization of the dopamine transporter with the new selective ligand [125]PE2I. Neuroimage 9, 108-116. doi: 10.1006/nimg.1998.0366

Hampson, D. R., and Blatt, G. J. (2015). Autism spectrum disorders and neuropathology of the cerebellum. Front. Neurosci. 9:420. doi: 10.3389/fnins.2015.00420

Happe, H. K., Coulter, C. L., Gerety, M. E., Sanders, J. D., O’Rourke, M., Bylund, D. B., et al. (2004). Alpha-2 adrenergic receptor development in rat CNS: an autoradiographic study. Neuroscience 123, 167-178. doi: 10.1016/j.neuroscience.2003.09.004
Hayashi, M. (1987). Ontogeny of glutamic acid decarboxylase, tyrosine hydroxylase, choline acetyltransferase, somatostatin and substance $\mathrm{P}$ in monkey cerebellum. Brain Res. 429, 181-186. doi: 10.1016/0165-3806(87)90099-X

Heath, R. G., Franklin, D. E., Walker, C. F., and Keating, J. W. Jr. (1982). Cerebellar vermal atrophy in psychiatric patients. Biol. Psychiatry 17, 569-583.

Hioki, H., Fujiyama, F., Taki, K., Tomioka, R., Furita, T., Tamamak, N., et al. (2003). Differential distribution of vesicular glutamate transporters in the rat cerebellar cortex. Neuroscience 117, 1-6. doi: 10.1016/S0306-4522(02)00943-0

Hirono, M., Nagao, S., and Obata, K. (2014). Developmental $\alpha_{2}$-adrenergic regulation of noradrenergic synaptic facilitation at cerebellar GABAergic synapses. Neuroscience 256, 242-251. doi: 10.1016/j.neuroscience.2013.10.030

Hirono, M., and Obata, K. (2006). Alpha-adrenoceptive dual modulation of inhibitory GABAergic inputs to Purkinje cells in the mouse cerebellum. J. Neurophysiol. 95, 700-708. doi: 10.1152/jn.00711.2005

Hökfelt, T., and Fuxe, K. (1969). Cerebellar monoamine nerve terminals, a new type of afferent fibers to the cortex cerebelli. Exp. Brain Res. 9, 63-72. doi: $10.1007 / \mathrm{BF} 00235452$

Hökfelt, T., Johansson, O., and Goldstein, M. (1984). "Central catecholamine neurons as revealed by immunohistochemistry with special reference to adrenaline neurons," in Handbook of Chemical Neuroanatomy, Vol 2, Part 1, eds A. Björklund and T. Hökfelt (Amsterdam: Elsevier), 157-276.

Holloway, Z. R., Paige, N. B., Comstock, J. F., Nolen, H. G., Sable, H. J., and Lester, D. B. (2019). Cerebellum modulation of mesolimbic dopamine transmission is functionally asymmetrical. Cerebellum 18, 922-931. doi: 10.1007/s12311-019-01074-w

Hosp, J. A., Coenen, V. A., Rijntjes, M., Egger, K., Urbach, H., Weiller, C., et al. (2019). Ventral tegmental area connections to motor and sensory cortical fields in humans. Brain Struct. Funct. 224, 2839-2855. doi: 10.1007/s00429-019-01939-0

Hurley, M. J., Mash, D. C., and Jenner, P. (2003). Markers for dopaminergic neurotransmission in the cerebellum in normal individuals and patients with Parkinson's disease examined by RT-PCR. Eur. J. Neurosci. 18, 2668-2672. doi: 10.1046/j.1460-9568.2003.02963.x

Ikai, Y., Takada, M., Shinonaga, Y., and Mizuno, N. (1992). Dopaminergic and non-dopaminercic neurons in the ventral tegmental area of the rat project, resepectively, to the cerebellar cortex and deep cerebellar nuclei. Neuroscience 51, 719-728. doi: 10.1016/0306-4522(92)90310-X

Ito, M. (2009). Functional roles of neuropeptides in cerebellar circuits. Neuroscience 162, 666-672. doi: 10.1016/j.neuroscience.2009.01.019

Jaarsma, D., Ruigrok, T. J., Caffè, R., Cozzari, C., Levey, A. I., Mugnaini, E., et al. (1997). Cholinergic innervation and receptors in the cerebellum. Prog. Brain Res. 114, 67-96. doi: 10.1016/S0079-6123(08)63359-2

Jbabdi, S., and Johansen-Berg, H. (2011). Tractography: where do we go from here? Brain Connect. 1, 169-183. doi: 10.1089/brain.2011.0033

Jellinger, K. A. (1999). Post mortem studies in Parkinson's disease-is it possible to detect brain areas for specific symptoms? J. Neural. Transm. Suppl. 56, 1-29. doi: 10.1007/978-3-7091-6360-3_1

Jellinger, K. A. (2017). Neuropathology of nonmotor symptoms of Parkinson's disease. Int. Rev. Neurobiol. 133, 13-62. doi: 10.1016/bs.irn.2017.05.005

Jeurissen, B., Tournier, J. D., Dhollander, T., Connelly, A., and Sijbers, J. (2014). Multi-tissue constrained spherical deconvolution for improved analysis of multi-shell diffusion MRI data. Neuroimage 103, 411-426. doi: 10.1016/j.neuroimage.2014.07.061

Jiang, D., Lu, X., Li, Z., Rydberg, N., Zuo, C., Peng, F., et al. (2019). Increased vesicular monoamine transporter 2 (VMAT2) and dopamine transporter (DAT) expression in adolescent brain development: a longitudinal micro-PET/CT study in rodent. Front Neurosci. 12:1052. doi: 10.3389/fnins.2018.01052

Joo, K. M., Chung, Y. H., Kim, M. K., Nam, R. H., Lee, B. L., Lee, K. H., et al. (2004). Distribution of vasoactive intestinal polypeptide and pituitary adenylate cyclase-activating polypeptide receptors (VPAC1, VPAC2, and PAC1 receptor) in the rat brain. J. Comp. Neurol. 476, 388-413. doi: 10.1002/cne. 20231

Joseph, B., Nandhu, M. S., and Paulose, C. S. (2010). Dopamine D1 and D2 receptor functional down regulation in the cerebellum of hypoxic neonatal rats: neuroprotective role of glucose and oxygen, epinephrine resuscitation. Pharmacol. Res. 61, 136-141. doi: 10.1016/j.phrs.2009.08.007 
Kahle, P. J., Neumann, M., Ozmen, L., Muller, V., Jacobsen, H., Schindzielorz, A., et al. (2000). Subcellular localization of wild-type and Parkinson's diseaseassociated mutant alpha -synuclein in human and transgenic mouse brain. $J$. Neurosci. 20, 6365-6373. doi: 10.1523/JNEUROSCI.20-17-06365.2000

Kano, M., Rexhausen, U., Dreessen, J., and Konnerth, A. (1992). Synaptic excitation produces a long-lasting rebound potentiation of inhibitory synaptic signals in cerebellar Purkinje cells. Nature 356, 601-604. doi: 10.1038/356601a0

Kawaguchi, S. Y., and Hirano, T. (2002). Signaling cascade regulating long-term potentiation of $\mathrm{GABA}(\mathrm{A})$ receptor responsiveness in cerebellar Purkinje neurons. $J$ Neurosci. 22, 3969-3976. doi: 10.1523/JNEUROSCI.22-10-03969.2002

Kemper, T. L., and Bauman, M. L. (1993). The contribution of neuropathologic studies to the understanding of autism. Neurol. Clin. 11, 175-187. doi: 10.1016/S0733-8619(18)30176-2

Kerr, C. W., and Bishop, G. A. (1991). Topographical organization in the origin of serotoninergic projections to different regions of the cat cerebellar cortex. J. Comp. Neurol. 304, 502-515. doi: 10.1002/cne.903040313

Kerr, C. W., and Bishop, G. A. (1992). The physiological effects of serotonin are mediated by the 5HT1A receptor in the cat's cerebellar cortex. Brain Res. 591, 253-260. doi: 10.1016/0006-8993(92)91705-J

Khan, Z., Gutiérrez, A., Martin, R., Peñafiel, A., Rivera, A., and de la Calle, A. (1998). Differential regional and cellular distribution of dopamine D2-like receptors: an immunocytochemical study of subtypespecific antibodies in rat and human brain. J. Comp. Neurol. 402, 353-371. doi: 10.1002/(SICI)1096-9861(19981221)402:3andlt;353::AIDCNE5andgt;3.0.CO;2-4

Khan, Z., Gutierrez, A., Martin, R., Penafiel, A., Rivera, A., and de la Calle, A. (2000). Dopamine D5 receptors of rat and human brain. Neuroscience 100, 689-699. doi: 10.1016/S0306-4522(00)00274-8

Kim, Y. S., Shin, J. H., Hall, F. S., and Linden, D. J. (2009). Dopamine signalling is required for depolarization induced slow current in cerebellar Purkinje cells. J. Neurosci. 29, 8530-8538. doi: 10.1523/JNEUROSCI.0468-09.2009

King, J. S., Cummings, S. L., and Bishop, G. A. (1992). Peptides in cerebellar circuits. Prog. Neurobiol. 39, 423-442. doi: 10.1016/0301-0082(92) 90014-6

Kingsbury, A. E., Daniel, S. E., Sangha, H., Eisen, S., Lees, A. J., and Foster, O. J. (2004). Alteration in alpha-synuclein mRNA expression in Parkinson's disease. Mov. Disord. 19, 162-170. doi: 10.1002/mds.10683

Kiss, B., Horti, F., and Bobok, A. (2011). In vitro and in vivo comparison of $\left[{ }^{3} \mathrm{H}\right](+)$-PHNO and $\left[{ }^{3} \mathrm{H}\right]$ raclopride binding to rat striatum and lobes 9 and 10 of the cerebellum: a method to distinguish dopamine $\mathrm{D} 3$ from $\mathrm{D}_{2}$ receptor sites. Synapse 65, 467-478. doi: 10.1002/syn.20867

Kitzman, P. H., and Bishop, G. A. (1994). The origin of serotoninergic afferents to the cat's cerebellar nuclei. J. Comp. Neurol. 340, 541-550. doi: 10.1002/cne.903400407

Kitzman, P. H., and Bishop, G. A. (1997). The effects of serotonin on spontaneous and amino acid-induced activation of cerebellar nuclear cells: an in vivo study in the cat. Prog. Brain Res. 114, 209-223. doi: 10.1016/S0079-6123(08)63366-X

Kizer, J. S., Palkovits, M., and Brownstein, M. J. (1976). The projections of the A8, A9 and A10 dopaminergic cell bodies: evidence for a nigralhypothalamic-median eminence dopaminergic pathway. Brain Res. 108, 363-370. doi: 10.1016/0006-8993(76)90192-X

Knöpfel, T., and Grandes, P. (2002). Metabotropic glutamate receptors in the cerebellum with a focus on their function in Purkinje cells. Cerebellum 1, 19-26. doi: 10.1007/BF02941886

Koch, G. (2010). rTMS effects on levodopa induced dyskinesias in Parkinson's disease patients: searching for effective targets. Restor. Neurol. Neurosci. 28, 561-568. doi: 10.3233/RNN-2010-0556

Kolasiewicz, W., Kuter, K., Berghauzen, K., Nowak, P., Schulze, G., and Ossowska, K. (2012). 6-OHDA injections into A8-A9 dopaminergic neurons modelling early stages of Parkinson's disease increase the harmaline-induced tremor in rats. Brain Res. 1477, 59-73. doi: 10.1016/j.brainres.2012.08.015

Koziol, L. F., Budding, D., Nancy Andreasen, A., D’Arrigo, S., Bulgheroni, S., Imamizu, H., et al. (2014). Consensus paper: the cerebellum's role in movement and cognition. Cerebellum 13, 151-177. doi: 10.1007/s12311-013-0511-x

Kühn, S., Romanowski, A., Schubert, F., and Gallina, J. (2012). Reduction of cerebellar grey matter in Crus I and II in schizophrenia. Brain Struct. Funct. 217, 523-529. doi: 10.1007/s00429-011-0365-2
Kwong, W. H., Chan, W. Y., Lee, K. K., Fan, M., and Yew, D. T. (2000). Neurotransmitters, neuropeptides and calcium binding proteins in developing human cerebellum: a review. Histochem. J. 32, 521-534. doi: 10.1023/A:1004197210189

Laidi, C., d'Albis, M. A., Wessa, M., Linke, J., Phillips, M. L., Delavest, M., et al. (2015). Cerebellar volume in schizophrenia and bipolar I disorder with and without psychotic features. Acta Psychiatr. Scand. 131, 223-233. doi: 10.1111/acps.12363

Landis, S. C., and Bloom, F.E. (1975). Ultrastructural identification of noradrenergic boutons in mutant and normal mouse cerebellar cortex. Brain Res. 96, 299-305. doi: 10.1016/0006-8993(75)90738-6

Larsell, O. (1952). The morphogenesis and adult pattern of the lobules and fissures of the cerebellum of the white rat. J. Comp. Neurol. 97, 281-356. doi: 10.1002/cne.900970204

Lawal, H. O., and Krantz, D. E. (2013). SLC18: vesicular neurotransmitter transporters for monoamines and acetylcholine. Mol. Aspects Med. 34, 360-372. doi: 10.1016/j.mam.2012.07.005

Lazarov, N. E., Schmidt, U., Wanner, I., and Pilgrim, C. (1998). Mapping of D1 dopamine receptor mRNA by non-radioactive in situ hybridization. Histochem. Cell. Biol. 109, 271-279. doi: 10.1007/s004180050227

Levant, B. (1998). Differential distribution of D3 dopamine receptors in the brains of several mammalian species. Brain Res. 800, 269-274. doi: 10.1016/S0006-8993(98)00529-0

Lewis, M. M., Galley, S., Johnson, S., Stevenson, J., Huang, X., and McKeown, M. J. (2013). The role of the cerebellum in the pathophysiology of Parkinson's disease. Can. J. Neurol. Sci. 40, 299-306. doi: 10.1017/S0317167100014232

Lindvall, O., and Björklund, A. (1974). The organization of the ascending catecholamines neuron systems in the rat brain as revealed by the glyoxilic acid fluorescence method. Acta Physiol. Scand. Suppl. 412, 1-48.

Lippiello, P., Hoxha, E., Volpicelli, F., Lo Duca, G., Tempia, F., and Miniaci, M. C. (2015). Noradrenergic modultion of the parallel fiberPurkinje cell synapse in mouse cerebellum. Neuropharmacology 89, 33-42. doi: 10.1016/j.neuropharm.2014.08.016

Locke, T. M., Fujita, H., Hunker, A., Johanson, S. S., Darvas, M., du Lac, S., et al. (2020). Purkinje cell-specific knockout of tyrosine hydroxylase impairs cognitive behaviors. Front Cell Neurosci. 14:228. doi: 10.3389/fncel.2020.00228

Locke, T. M., Soden, M. E., Miller, S. M., Hunker, A., Knakal, C., Licholai, J., et al. (2018). Dopamine D1 receptor-positive neurons in the lateral nucleus of the cerebellum contribute to cognitive behavior. Biol. Psychiatry 84, 401-412. doi: 10.1016/j.biopsych.2018.01.019

López, J. M., Morona, R., and González, A. (2010). Immunohistochemical localization of DARPP-32 in the brain spinal cord of anuran amphibians and its relation with the catecholaminergic system. J. Chem. Neuroanat. 40, 325-338. doi: 10.1016/j.jchemneu.2010.09.004

Lundkvist, C., Halladin, C., Swahn, C. G., Hall, H., Karlsson, P., Nakashima, Y., et al. (1995). [O-methyl-11C]beta-CIT-FP, a potential radioligand for quantification of the dopamine transporter: preparation, autoradiography, metabolite studies, and positron emission tomography examinations. Nucl. Med. Biol. 22:905-913. doi: 10.1016/0969-8051(95)00029-W

Maeshima, T., Shutoh, F., Hamada, S., Senzaki, K., Hamaguchi-Hamada, K., Ito, R., et al. (1998). Serotonin2A receptor-like immunoreactivity in rat cerebellar Purkinje cells. Neurosci. Lett. 252, 72-74. doi: 10.1016/S0304-3940(98)00546-1

Mapelli, L., Pagani, M., Garrido, J. A., and D’Angelo, E. (2015). Integrated plasticity at inhibitory and excitatory synapses in the cerebellar circuit. Front. Cell. Neurosci. 9:169. doi: 10.3389/fncel.2015.00169

Maric, D. (2010). Qualitative and Quantitative Analysis of the Adult Human Dentate Nucleus Neurons Morphology. University of Novi Sad, Belgrade, Serbia

Marinova, Z., Monoranu, C. M., Fetz, S., Walitza, S., and Grünblatt, E. (2015). Region-specific regulation of the serotonin 2A receptor expression in development and ageing in post mortem human brain. Neuropathol. Appl. Neurobiol. 41, 520-532. doi: 10.1111/nan.12167

Martin, P., and Albers, M. (1995). Cerebellum and schizophrenia: a selective review. Schizophr. Bull. 21, 241-250. doi: 10.1093/schbul/21.2.241

Martinu, K., Nagano-Saito, A., Fogel, S., and Monchi, O. (2014). Asymmetrical effect of levodopa on the neural activity of motor regions in PD. PLoS ONE 9:e111600. doi: 10.1371/journal.pone.0111600

Martres, M. P., Sales, N., Bouthenet, M. L., and Schwartz, J. C. (1985). Localisation and pharmacological characterisation of D-2 dopamine receptors in rat cerebral 
neocortex and cerebellum using [125I]iodosulpride. Eur. J. Pharmacol. 118, 211-219. doi: 10.1016/0014-2999(85)90131-1

Masilamoni, G., Votaw, J., Howell, L., Villalba, R. M., Goodman, M., Voll, R. J., et al. (2010). (18)F-FECNT: validation as PET dopamine transporter ligand in Parkinsonism. Exp. Neurol. 226, 265-273. doi: 10.1016/j.expneurol.2010.08.024

McCune, S. K., Voigt, M. M., and Hill, J. M. (1993). Expression of multiple alpha adrenergic receptor subtype messenger RNAs in the adult rat brain. Neuroscience 57, 143-151. doi: 10.1016/0306-4522(93)90116-W

Mefford, I. N., Foutz, A., Noyce, N., Jurik, S. M., Handen, C., Dement, W. C., et al. (1982). Distribution of norepinephrine, epinephrine, dopamine, serotonin, 3,4dihydroxyphenylacetic acid, homovanillic acid and 5-hydroxyindole-3-acetic acid in dog brain. Brain Res. 236, 339-349. doi: 10.1016/0006-8993(82)90719-3

Melchitzky, D. S., and Lewis, D. A. (2000). Tyrosine hydroxylase- and dopamine transporter- immunoreactive axons in the primate cerebellum. Evidence for a lobular- and laminar specific dopamine innervation. Neuropsychopharmacology 22, 466-472. doi: 10.1016/S0893-133X(99)00139-6

Melka, M. G., Castellani, C. A., Laufer, B. I., Rajakumar, R. N., O’Reilly, R., and Singh, S. M. (2013). Olanzapine induced DNA methylation changes support the dopamine hypothesis of psychosis. J. Mol. Psychiatry 1:19. doi: 10.1186/2049-9256-1-19

Mengod, G., Villaró, M. T., Landwehrmeyer, G. B., Martinez-Mir, M. I., Niznik, H. B., Sunahara, R. K., et al. (1992). Visualization of dopamine D1, D2 and D3 receptor mRNAs in human and rat brain. Neurochem. Int. Suppl. 33S-43S. doi: 10.1016/0197-0186(92)90208-9

Milardi, D., Arrigo, A., Anastasi, G., Cacciola, A., Marino, S., Mormina, E., et al. (2016). Extensive direct subcortical cerebellum-basal ganglia connections in human brain as revealed by constrained spherical deconvolution tractography. Front. Neuroanat. 10:29. doi: 10.3389/fnana.2016.00029

Miquel, M., Gil-Miravet, I., and Guarque-Chabrera, J. (2020). The cerebellum on cocaine. Front. Syst. Neurosci. 14:586574. doi: 10.3389/fnsys.2020.586574

Miterko, L. N., Baker, K. B., Beckinghausen, J., Bradnam, L. V., Cheng, M. Y., Cooperrider, J., et al. (2019). Consensus paper: experimental neurostimulation of the cerebellum. Cerebellum 18, 1064-1097. doi: 10.1007/s12311-01901041-5

Mitoma, H., and Konishi, S. (1996). Long-lasting facilitation of inhibitory transmission by monoaminergic and cAMP-dependent mechanism in rat cerebellar GABAergic synapses. Neurosci. Lett. 217, 141-144. doi: 10.1016/0304-3940(96)13090-1

Mitoma, H., and Konishi, S. (1999). Monoaminergic long-term facilitation of GABA-mediated inhibitory transmission at cerebellar synapses. Neuroscience 88, 871-883. doi: 10.1016/S0306-4522(98)00260-7

Mittleman, G., Goldowitz, D., Heck, D. H., and Blaha, C. D. (2008). Cerebellar modulation of frontal cortex dopamine efflux in mice: relevance to autism and schizophrenia. Synapse 62, 544-550. doi: 10.1002/syn.20525

Moises, H. C., Waterhouse, B. D., and Woodward, D. J. (1983). Locus coeruleus stimulation potentiates local inhibitory processes in rat cerebellum. Brain Res. Bull. 10, 795-804. doi: 10.1016/0361-9230(83)90211-3

Monti, B., Polazzi, E., Batti, L., Crochemore, C., Virgili, M., and Contestabile, A. (2007). Alpha-synuclein protects cerebellar granule neurons against 6-hydroxydopamine-induced death. J. Neurochem. 103, 518-530. doi: 10.1111/j.1471-4159.2007.04778.x

Mori, F., Piao, Y. S., Hayashi, S., Fujiwara, H., Hasegawa, M., Yoshimoto, M., et al. (2003). Alpha-synuclein accumulates in Purkinje cells in Lewy body disease but not in multiple system atrophy. J. Neuropathol. Exp. Neurol. 62, 812-819. doi: 10.1093/jnen/62.8.812

Mosconi, M. W., Wang, Z., Schmitt, L. M., Tsai, P., and Sweeney, J. A. (2015). The role of cerebellar circuitry alterations in the pathophysiology of autism spectrum disorders. Front. Neurosci. 9:296. doi: 10.3389/fnins.2015.00296

Mouatt-Prigent, A., Karlsson, J. O., Yelnik, J., Agid, Y., and Hirsch, E. C. (2000). Calpastatin immunoreactivity in the monkey and human brain of control subjects and patients with Parkinson's disease. J. Comp. Neurol. 419, 175-192. doi: 10.1002/(SICI)1096-9861(20000403)419:2andlt;175::AIDCNE3andgt;3.0.CO;2-2

Mugnaini, E., Sekerková, G., and Martina, M. (2011). The unipolar brush cell: a remarkable neuron finally receiving deserved attention. Brain Res. Rev. 66, 220-245. doi: 10.1016/j.brainresrev.2010.10.001

Murano, M., Saitow, F., and Suzuki, H. (2011). Modulatory effects of serotonin on glutamatergic synaptic transmission and long-term depression in the deep cerebellar nuclei. Neuroscience 172, 118-128. doi: 10.1016/j.neuroscience.2010.10.037

Nelson, T. E., King, J. S., and Bishop, G. A. (1997). Distribution of tyrosine hydroxylase-immunoreactive afferents to the cerebellum differs between species. J. Comp. Neurol. 379, 443-454. doi: $\quad$ 10.1002/(SICI)1096-9861(19970317)379:3andlt;443::AID CNE9andgt;3.0.CO;2-3

Nieoullon, A., Chearmy, A., and Glowinski, J. (1978). Release of dopamine in both caudate nuclei and both substantia nigra in response to unilateral stimulation of cerebellar nuclei in the cat. Brain Res. 148, 143-152. doi: 10.1016/0006-8993(78)90384-0

Nieoullon, A., and Dusticier, N. (1980). Changes in dopamine release in caudate nuclei and substantia nigra after electrical stimulation of the posterior interposate nucleus of cat cerebellum. Neurosci. Lett. 17, 167-172. doi: 10.1016/0304-3940(80)90079-8

Nishi, A., and Shuto, T. (2017). Potential for targeting dopamine/DARPP-32 signalling in neuropsychiatric and neurodegenerative disorders. Expert Opin. Ther. Targets 21, 259-272. doi: 10.1080/14728222.2017.1279149

Nusser, Z., and Somogyi, P. (1997). Compartmentalised distribution of GABAA and glutamate receptors in relation to transmitter release sites on the surface cerebellar neurons. Prog. Brain Res. 114, 109-127. doi: 10.1016/S0079-6123(08)63361-0

Oades, R. D., and Halliday, G. M. (1987). Ventral tegmental (A10) system: neurobiology. 1. Anatomy and connectivity. Brain 434, 117-165. doi: 10.1016/0165-0173(87)90011-7

Oberman, L. M., Enticott, P. G., Casanova, M. F., Rotenberg, A., Pascual-Leone, A., and McCracken, J. T. (2016). TMS in ASD Consensus Group. Transcranial magnetic stimulation in autism spectrum disorder: challenges, promise, and roadmap for future research. Autism Res. 9, 184-203. doi: 10.1002/aur.1567

Oertel, W. H. (1993). Neurotransmitters in the cerebellum. Scientific aspects and clinical relevance. Adv. Neurol. 61, 33-75.

O'Hallaran, C. J., Kinsella, G. J., and Storey, E. (2012). The cerebellum and neuropsychological functioning: a critical review. J. Clin. Exp. Neuropsychol. 34, 35-56. doi: 10.1080/13803395.2011.614599

O'Leary, K. T., and Leslie, F. M. (2003). Developmental regulation of nicotinc acetylcholine receptor-mediated $[3 \mathrm{H}]$ norepinephrine release from rat cerebellum. J. Neurochem. 84, 952-959. doi: 10.1046/j.1471-4159.2003.01575.x

Oostland, M., Buijink, M. R., and van Hooft, J. A. (2013). Serotonergic control of Purkinje cell maturation and climbing fibre elimination by 5HT3 receptors in the juvenile mouse cerebellum. J. Physiol. 591, 1793-1807. doi: 10.1113/jphysiol.2012.246413

Oostland, M., and van Hooft, J. A. (2013). The role of serotonin in cerebellar development. Neuroscience 248, 201-212. doi: 10.1016/j.neuroscience.2013.05.029

Ottersen, O. P. (1993). Neurotransmitter in the cerebellum. Rev. Neurol. $149,629-636$.

Panagopoulos, N. T., and Matsokis, N. A. (1994). Pharmacologic characterization of $[3 \mathrm{H}]$ dopamine and $[3 \mathrm{H}]$ spiperone binding in mouse cerebellum. Gen. Pharmacol. 25, 131-137. doi: 10.1016/0306-3623(94)90022-1

Panagopoulos, N. T., Papadopoulos, G. C., and Matsokis, N. A. (1991) Dopaminergic innervation and binding in the rat cerebellum. Neurosci. Lett. 130, 208-212. doi: 10.1016/0304-3940(91)90398-D

Parker, K. L., Narayanan, N. S., and Andreasen, N. C. (2014). The therapeutic potential of the cerebellum in schizophrenia. Front. Syst. Neurosci. 8:163. doi: $10.3389 /$ fnsys.2014.00163

Pasinetti, G. M., Johnson, S. A., Oda, T., Rozovsky, I., and Finch, C. E. (1994). Clusterin (SGP-2): a multifunctional glycoprotein with regional expression in astrocytes and neurons of the adult rat brain. J. Comp. Neurol. 339, 387-400. doi: 10.1002/cne.903390307

Pasqualetti, M., Ori, M., Nardi, I., Castagna, M., Cassano, G. B., and Marazziti, D. (1998). Distribution of the 5-HT5A serotonin receptor mRNA in the human brain. Brain Res. Mol. Brain Res. 56, 1-8. doi: 10.1016/S0169-328X(98)00003-5

Pasquier, D. A., Gold, M. A., and Jacobowitz, D. M. (1980). Noradrenergic perikarya (A5-A7, subcoeruleus) projections to the rat cerebellum. Brain Res. 196, 270-275. doi: 10.1016/0006-8993(80)90737-4

Pauli, W. M., Nili, A. N., and Michael Tyszka, J. (2018). Data Descriptor: a highresolution probabilistic in vivo atlas of human subcortical brain nuclei. Sci. Data. 5:180063. doi: 10.1038/sdata.2018.63 
Perciavalle, V., Apps, R., Bracha, V., Delgado-Garcia, J. M., Gibson, A. R., Leggio, M., et al. (2013). Consensus paper: currents views on the role of cerebellar interpositus nucleus in movement control and emotion. Cerebellum 12, 738-757. doi: 10.1007/s12311-013-0464-0

Phillips, J. R., Hewedi, D. H., Eissa, A. M., and Moustafa, A. A. (2015). The cerebellum and psychiatric disorders. Front. Public. Health. 3:66. doi: $10.3389 /$ fpubh.2015.00066

Piao, Y., Mori, F., Hayashi, S., Tanji, K., Yoshimoto, M., Kakit, A., et al. (2003). Alpha-, pathology affecting Bergmann glia of the cerebellum in patients with alpha-synucleinopathies. Acta Neuropathol. 105, 403-409. doi: 10.1007/s00401-002-0655-0

Pickel, V. M., Krebs, H., and Bloom, F. E. (1973). Proliferation of norepinephrinecontaining axons in rat cerebellar cortex after peduncle lesions. Brain Res. 59, 169-179. doi: 10.1016/0006-8993(73)90258-8

Pinacho, R., Villalmanzo, N., Roca, M., Iniesta, R., Monje, A., Haro, J. M., et al. (2013). Analysis of Sp transcription factors in the postmortem brain of chronic schizophrenia: a pilot study of relationship to negative symptoms. J. Psychiatr. Res. 47, 926-934. doi: 10.1016/j.jpsychires.2013.03.004

Pompeiano, M., Galbani, P., and Ronca-Testoni, S. (1989). Distribution of betaadrenergic receptors in different cortical and nuclear regions of cat cerebellum, as revealed by binding studies. Arch. Ital. Biol. 127, 115-132.

Pompeiano, O. (1998). Noradrenergic influences on the cerebellar cortex: effects on vestibular reflexes under basic and adaptive conditions. Otolaryngol. Head Neck Surg.119, 93-105. doi: 10.1016/S0194-5998(98)70178-0

Powers, R. E., O'Conner, D. T., and Price, D. L. (1989). Noradrenergic systems in human cerebellum. Brain Res. 481, 194-199. doi: 10.1016/0006-8993(89)90504-0

Prestori, F., Bonardi, C., Mapelli, L., Lombardo, P., Goselink, R., De Stefano, M. E., et al. (2013). Gating of long-term potentation by nicotinic acetylcholine receptors at the cerebellum input stage. PLOS ONE. 8:e64828. doi: 10.1371/journal.pone.0064828

Quansah, E., Ruiz-Rodado, V., Grootveld, M., and Zetterström, T. S. C. (2018). Methylphenidate alters monoaminergic and metabolic pathways in the cerebellum of adolescent rats. Eur. Neuropsychopharmacol. 28, 513-528. doi: 10.1016/j.euroneuro.2018.02.002

Quartarone, A., Cacciola, A., Milardi, A., Ghilardi, M. F., Calamuneri, A., Chillemi, A., et al. (2020). New insights into cortico-basal-cerebellar connectome: clinical and physiological considerations. Brain 143, 396-406. doi: 10.1093/brain/awz310

Raymond, J. R., Mukhin, Y. V., Gelasco, A., Turner, J., Collinsworth, G., Gettys, T. W., et al. (2001). Multiplicity of mechanisms of serotonin receptor signal transduction. Pharmacol. Ther. 92, 179-212. doi: $10.1016 /$ S0163-7258(01)00169-3

Reyes, M. G., and Gordon, A. (1981). Cerebellar vermis in schizophrenia. Lancet 2, 700-701. doi: 10.1016/S0140-6736(81)91039-4

Ricci, A., Mammola, C. L., Vega, J. A., Zaccheo, D., and Amenta, F. (1996). Density and pattern of dopamine D2-like receptors in the cerebellar cortex of aged rats. Neurobiol. Aging 17, 45-52. doi: 10.1016/0197-4580(95)02029-2

Ricci, A., Vega, J. A., Mammola, C. L., and Amenta, F. (1995a). Localisation of dopamine D3 receptor in the rat cerebellar cortex: a light microscope autoradiographic study. Neurosci. Lett. 190, 163-166. doi: 10.1016/0304-3940(95)11530-A

Ricci, A., Zaccheo, D., and Amenta, F. (1995b). Identification of age-related changes of dopamine D1-like receptors in the rat cerebellar cortex. Synapse 21, 37-44. doi: 10.1002/syn.890210106

Ristanović, D., Milosević, N. T., Stefanović, B. D., Marić, D. L., and Rajković, K. (2010). Morphology and classification of large neurons in the adult human dentate nucleus a qualitative and quantitative analysis of 2D images. Neurosci. Res. 67, 1-7. doi: 10.1016/j.neures.2010.01.002

Rogers, T. D., Dickson, P. E., McKimm, E., Heck, D. H., Goldowitz, D., Blaha, C. D., et al. (2013). Reorganization of circuits underlying cerebellar modulation of prefrontal cortical dopamine in mouse models of autism spectrum disorder. Cerebellum 12, 547-556. doi: 10.1007/s12311-013-0462-2

Rosin, D. L., Talley, E. M., Lee, A., Stornetta, R. L., Gaylinn, B. D., Guyenet, P. G., et al. (1996). Distribution alpha 2C-adrenergic receptor-like immunoreactivity in the rat central nervous system. J. Comp. Neurol. 372, 135-165. doi: 10.1002/(SICI)1096-9861(19960812)372:1 andlt;135::AID-CNE9andgt;3.0. $\mathrm{CO} ; 2-4$
Roubein, I. F., and Embree, L. J. (1979). Post mortem stability of catecholamines in discrete regions of rat brain. Res. Commun. Chem. Pathol. Pharmacol. $23,143-153$.

Sachs, C., Jonsson, G., and Fuxe, K. (1973). Mapping of central noradrenaline pathways with 6-hydroxy-DOPA. Brain Res. 63, 249-261. doi: 10.1016/0006-8993(73)90092-9

Saitow, F., Murano, M., and Suzuki, H. (2009). Modulatory effects of serotonin on GABAergic synaptic transmission and membrane properties in the deep cerebellar nuclei. J. Neurophysiol. 101, 1361-1374. doi: 10.1152/jn.90750.2008

Sanchez-Perez, A., Llansola, M., Cauli, O., and Felipo, V. (2005). Modulation of NMDA receptors in the cerebellum. II. Signalling pathways and physiological modulators regulating NMDA receptor function. Cerebellum 4, 162-170. doi: 10.1080/14734220510008003

Sari, Y., Miquel, M. C., Brisorgueil, M. J., Ruiz, G., Doucet, E., Hamon, M., et al. (1999). Cellular and subcellular localization of 5-hydroxytryptamine1B receptors in the rat central nervous system: immunocytochemical, autoradiographic and lesion studies. Neuroscience 88, 899-915. doi: 10.1016/S0306-4522(98)00256-5

Sasaki, K., Doh-ura, K., Wakisaka, Y., and Iwaki, T. (2002). Clusterin/apolipoprotein $\mathrm{J}$ is associated with cortical Lewy bodies: immunohistochemical study in cases with alpha-synucleinopathies. Acta Neuropathol. 104, 225-230. doi: 10.1007/s00401-002-0546-4

Sastry, B. R., Morishita, W., Yip, S., and Shew, T. (1997). GABA-ergic transmission in deep cerebellar nuclei. Prog. Neurobiol. 53, 259-271. doi: 10.1016/S0301-0082(97)00033-6

Schibusawa, N., Hashimoto, K., and Yamada, M. (2008). Thyrotropinreleasing hormone (TRH) in the cerebellum. Cerebellum 7, 84-95. doi: 10.1007/s12311-008-0033-0

Schmitt, A., Schulenberg, W., Bernstein, H. G., Steiner, J., Schneider-Axmann, T., Yeganeh-Doost, P., et al. (2011). Reduction of gyrification index in the cerebellar vermis in schizophrenia: a post-mortem study. World J. Biol. Psychiatry 12(Suppl 1), 99-103. doi: 10.3109/15622975.2011.598379

Schoeps, K. O., Halldin, C., Någren, K., Swahn, C. G., Karlsson, P., Hall, H., et al. (1993) Preparation of [1-11C]dopamine, [1-11C]p-tyramine and [1$11 \mathrm{C}] \mathrm{m}$-tyramine. Autoradiography and PET examination of [1-11C]dopamine in primates. Nucl. Med. Biol. 20, 669-678. doi: 10.1016/0969-8051(93)90038-v

Schutter, D. J., van Honk, J., d'Alfonso, A. A., Peper, J. S., and Panksepp, J. (2003). High frequency repetitive transcranial magnetic over the medial cerebellum induces a shift in the prefrontal electroencephalography gamma spectrum: a pilot study in humans. Neurosci. Lett. 336, 73-76. doi: 10.1016/S0304-3940(02)01077-7

Sievers, J., Berry, M., and Baumgarten, H. (1981). The role of noradrenergic fibers in the control of post-natal cerebellar development. Brain Res. 207, 200-208. doi: 10.1016/0006-8993(81)90694-6

Sievers, J., and Klemm, H. P. (1982). Locus coeruleus - cerebellum: interaction during development. Bibl. Anat. 23, 56-75.

Siggins, G. R., Hoffer, B. J., Oliver, A. P., and Bloom, F. E. (1971). Activation of a central noradrenergic projection to cerebellum. Nature 233, 481-483. doi: $10.1038 / 233481 \mathrm{a} 0$

Simioni, A. C., Dagher, A., and Fellows,. L. K. (2015). Compensatory striatalcerebellar connectivity in mild-moderate Parkinson's disease. Neuroimage Clin. 10, 54-62. doi: 10.1016/j.nicl.2015.11.005

Skefos, J., Cummings, C., Enzer, K., Holiday, J., Weed, K., and Levy, E. (2014). Regional alterations in Purkinje cell density in patients with autism. PLoS ONE 9:e81255. doi: 10.1371/journal.pone.00 81255

Snider, S. R. (1982). Cerebellar pathology in schizophrenia-cause or consequence? Neurosci. Biobehav. Rev. 6, 47-53. doi: 10.1016/0149-7634(82) 90006-9

Snider, S. R., and Maiti, A. (1976). Cerebellar contributions to the papez circuits J. Neurosci. Res. 2, 133-146. doi: 10.1002/jnr.490020204

Spokes, E. G. (1979). An analysis of factors influencing measurements of dopamine, noradrenaline, glutamate decarboxylase and choline acetylase in human post-mortem brain tissue. Brain 102, 333-346. doi: 10.1093/brain/102.2.333

Stevens, J. R. (1982). "Neurology and neuropathology of schizophrenia," in Schizophrenia and Brain Disease, eds F. A. Henn and H. S. Nasrallah (New York, NY: University Press), 112-147. 
Strahlendorf, J. C., Lee, M., and Strahlendorf, H. K. (1984). Effects of serotonin on cerebellar Purkinje cells are dependent on the baseline firing rate. Exp. Brain Res. 56, 50-58. doi: 10.1007/BF00237441

Strahlendorf, J. C., Lee, M. H., and Strahlendorf, H. K. (1991). Serotonin modulates muscimol- and baclofen-elicited inhibition of cerebellar Purkinje cells. Eur. J. Pharmacol. 201, 239-242. doi: 10.1016/0014-2999(91)90352-Q

Strick, P. L., Dum, R. P., and Fiez, J. A. (2009). Cerebellum and nonmotor function. Annu. Rev. Neurosci. 32, 413-434. doi: 10.1146/annurev.neuro.31.060407.125606

Tabata, T., and Kano, M. (2006). GABA (B) receptor-mediated modulation of glutamate signalling in cerebellar Purkinje cells. Cerebellum 5, 127-133. doi: 10.1080/14734220600788911

Takada, M., Sugimoto, T., and Hattori, T. (1993). Tyrosine hydroxylase immunoreactivity in cerebellar Purkinje cells of the rat. Neurosci. Lett. 150, 61-64. doi: 10.1016/0304-3940(93)90108-W

Takahashi, H., and Wakabayashi, K. (2001). The cellular pathology of Parkinson's disease. Neuropathology 21, 315-322. doi: 10.1046/j.1440-1789.2001.00403.x

Takeuchi, Y., Kimura, H., and Sano, Y. (1982). Immunohistochemical demonstration of the distribution of serotonin neurons in the brainstem of the rat and cat. Cell. Tissue Res. 224, 247-267. doi: 10.1007/BF00216872

Talley, E. M., Rosin, D. L., Lee, A., Guynet, P. G., and Lynch, K. R. (1996). Distribution of alpha 2A-adrenergic receptor-like immunoreactivity in the rat central nervous system. J. Comp. Neurol. 372, 111-134. doi: 10.1002/(SICI)1096-9861(19960812)372:1andlt;111::AIDCNE8andgt;3.0.CO;2-6

Tan, E. K., Chandran, V. R., Fook-Chong, S., Shen, H., Yew, K., Teoh, M. L., et al. (2005). Alpha-synuclein mRNA expression in sporadic Parkinson's disease. Mov. Disord. 20, 620-623. doi: 10.1002/mds.20391

Törk, I. (1990). Anatomy of the serotonergic system. Ann. N. Y. Acad. Sci. 600, 9-34. doi: 10.1111/j.1749-6632.1990.tb16870.x

Tran, K. D., Smutzer, G. S., Doty, R. L., and Arnold, S. E. (1998). Reduced Purkinje cell size in the cerebellar vermis of elderly patients with schizophrenia. Am. J. Psychiatry 155, 1288-1290. doi: 10.1176/ajp.155.9.1288

Trutti, A. C., Mulder, M. J., Hommel, B., and Forstmann, B. U. (2019). Functional neuroanatomical review of the ventral tegmental area. Neuroimage 191, 258-268. doi: 10.1016/j.neuroimage.2019.01.062

Uusisaari, M., and De Schutter, E. (2011). The mysterious microcircuitry of the cerebellar nuclei. J. Physiol. 589, 3441-3457. doi: 10.1113/jphysiol.2010.201582

Uzunova, G., Pallanti, S., and Hollander, E. (2016). Excitatory/inhibitory imbalance in autism spectrum disorders: Implications for interventions and therapeutics. World J. Biol. Psychiatry 17, 174-186. doi: 10.3109/15622975.2015.10 85597

van Dun, K., Bodranghien, F., Manto, M., and Mariën, P. (2017). Targeting the cerebellum by noninvasive neurostimulation: a review. Cerebellum 16, 695-741. doi: 10.1007/s12311-016-0840-7

Van Essen, D. C., Smith, S. M., Barch, D. M., Behrens, T. E. J., Yacoub, E., and Ugurbil, K. (2013). The WU-Minn human connectome project: an overview. Neuroimage 80, 62-79. doi: 10.1016/j.neuroimage.2013.05.041

Varrone, A., Steiger, C., Schou, M., Takano, A., Finnema, S. J., Guilloteau, D., et al. (2009). In vitro autoradiography and in vivo evaluation in cynomolgus monkey of [18F]FE-PE2I, a new dopamine transporter PET radioligand. Synapse. 63, 871-880. doi: 10.1002/syn.20670

Verney, C., Gaspar, P., Febvret, A., and Berger, B. (1988). Transient tyrosine hydroxylase-like immunoreactive neurons contain somatostatin and substance $\mathrm{P}$ in the developing amygdala and bed nucleus of the stria terminalis of the rat. Dev. Brain Res. 42, 45-58. doi: 10.1016/0165-3806(88) 90200-3

Versteeg, D. H., Van Der Gugten, J., De Jong, W., and Palkovits, M. (1976). Regional concentrations of noradrenaline and dopamine in rat brain. Brain Res. 113, 563-574. doi: 10.1016/0006-8993(76)90057-3

Vessotskie, J. M., Kung, M. P., Chumpradit, S., and Kung, H. F. (1997). Quantitative autoradiographic studies of dopamine D3 receptors in rat cerebellum using [125I]S(-)5-OH-PIPAT. Brain Res. 778, 89-98. doi: 10.1016/S0006-8993(97)01014-7

Voogd, J., Gerrits, N. M., and Ruigrok, T. J. (1996). Organization of the vestibulocerebellum. Ann. N. Y. Acad. Sci. 781, 553-579. doi: 10.1111/j.1749-6632.1996.tb15728.x

Wang, Y., Strahlendorf, J. C., and Strahlendorf, H. K. (1992). Serotonin reduces a voltage-dependent transient outward potassium current and enhances excitability of cerebellar Purkinje cells. Brain Res. 571, 345-349. doi: 10.1016/0006-8993(92)90675-Y

Weinberger, D. R., Kleinman, J. E., Luchins, D. J., Bigelow, L. B., and Wyatt, R. J. (1980). Cerebellar pathology in schizophrenia: a controlled postmortem study. Am. J. Psychiatry 137, 359-361. doi: 10.1176/ajp.137.3.359

Westerlund, M., Belin, A. C., Anvret, A., Håkansson, A., Nissbrandt, H., Lind, C., et al. (2008). Cerebellar alpha-synuclein levels are decreased in Parkinson's disease and do not correlate with SNCA polymorphisms associated with disease in a Swedish material. FASEB J. 22, 3509-3514. doi: 10.1096/fj.08-110148

White, R. B., and Thomas, M. G. (2012). Moving beyond tyrosine hydroxylase to define dopaminergic neurons for use in cell replacement therapies for Parkinson's disease. CNS Neurol. Disord. Drug Targets 11, 340-349. doi: 10.2174/187152712800792758

Whitney, E. R., Kemper, T. L., Bauman, M. L., Rosene, D. L., and Blatt, G. J. (2008). Cerebellar Purkinje cells are reduced in a subpopulation of autistic brains:a stereological experiment using calbindin-D28k. Cerebellum 7 , 406-416. doi: 10.1007/s12311-008-0043-y

Wisden, W., Korpi, E. R., and Bahn, S. (1996). The cerebellum: a model system for studying GABAA receptor diversity. Neuropharmacology 35, 1139-1160. doi: 10.1016/S0028-3908(96)00076-7

Woodward, D. J., Moises, H. C., Waterhouse, B. D., Yeh, H. H., and Cheun, J. E. (1991). The cerebellar norepinephrine system: inhibition, modulation, and gating. Prog. Brain Res. 88, 331-341. doi: 10.1016/S0079-6123(08)63820-0

Wu, T., and Hallett, M. (2013). The cerebellum in Parkinson's disease. Brain 136, 696-670. doi: 10.1093/brain/aws360

Wuenschell, C. W., Fisher, R. S., Kaufman, D. L., and Tobin, A. J. (1986). In situ hybridization to localize mRNA encoding the neurotransmitter synthetic enzyme glutamate decarboxylase in mouse cerebellum. Proc. Natl. Acad. Sci. U.S.A. 83, 6193-6197. doi: 10.1073/pnas.83.16.6193

Yagishita, S., Hayashi-Takagi, A., Ellis-Davies, G. C., Urakubo, H., Ishii, S., and Kasai, H. (2014). A critical time window for dopamine actions on the structural plasticity of dendritic spines. Science 345, 1616-1620. doi: $10.1126 /$ science. 1255514

Yamamoto, T., Ishikawa, M., and Tanaka, C. (1977). Catecholaminergic terminals in the developing and adult rat cerebellum. Brain Res. 132, 355-361. doi: 10.1016/0006-8993(77)90428-0

Yew, D. T., Luo, C. B., Shen, W. Z., Chow, P. H., Zheng, D. R., and Yu, M. C. (1995) Tyrosine hydroxylase- and dopamine-beta-hydroxylase-positive neurons and fibres in the developing human cerebellum-an immunohistochemical study. Neuroscience 65, 453-461. doi: 10.1016/0306-4522(94)00521-6

Yoo, H. S., Choi, Y. H., Chung, S. J., Lee, Y. H., Ye, B. S., Sohn, Y. H., et al. (2019). Cerebellar connectivity in Parkinson's disease with levodopa-induced dyskinesia. Ann. Clin. Transl. Neurol. 6, 2251-2260. doi: 10.1002/acn3.50918

Zhang, C., Zhou, P., and Yuan, T. (2016). The cholinergic system in the cerebellum: from structure to function. Rev. Neurosci. 27, 769-776. doi: 10.1515/revneuro-2016-0008

Zhang, N., and Ottersen, O. P. (1993). In search of the identity of the cerebellar climbing fiber transmitter: immunocytochemical studies in rats. Can. J. Neurol. Sci. 20(Suppl 3), S36-S42. doi: 10.1017/S0317167100048514

Conflict of Interest: The authors declare that the research was conducted in the absence of any commercial or financial relationships that could be construed as a potential conflict of interest.

Publisher's Note: All claims expressed in this article are solely those of the authors and do not necessarily represent those of their affiliated organizations, or those of the publisher, the editors and the reviewers. Any product that may be evaluated in this article, or claim that may be made by its manufacturer, is not guaranteed or endorsed by the publisher.

Copyright (c) 2021 Flace, Livrea, Basile, Galletta, Bizzoca, Gennarini, Bertino, Branca, Gulisano, Bianconi, Bramanti and Anastasi. This is an open-access article distributed under the terms of the Creative Commons Attribution License (CC BY). The use, distribution or reproduction in other forums is permitted, provided the original author(s) and the copyright owner(s) are credited and that the original publication in this journal is cited, in accordance with accepted academic practice. No use, distribution or reproduction is permitted which does not comply with these terms. 